\title{
Biophysical and structural studies reveal marginal stability of Acyl ACP Reductase: a crucial hydrocarbon biosynthetic enzyme
}

\section{Ashima Sharma}

International Centre For Genetic Engineering and Biotechnology New Delhi

\section{Tabinda Shakeel}

International Centre For Genetic Engineering and Biotechnology New Delhi

\section{Mayank Gupta}

International Centre For Genetic Engineering and Biotechnology New Delhi

\section{Girish Rajacharya}

International Centre For Genetic Engineering and Biotechnology New Delhi

Syed Shams Yazdani ( $\nabla$ shams@icgeb.res.in )

International Centre for Genetic Engineering and Biotechnology https://orcid.org/0000-0002-65584612

\section{Research}

Keywords: Acyl-ACP reductase, alkane, protein stability, CD spectroscopy, intrinsic fluorescence spectroscopy

Posted Date: October 23rd, 2020

DOl: https://doi.org/10.21203/rs.3.rs-96303/v1

License: (c) (1) This work is licensed under a Creative Commons Attribution 4.0 International License. Read Full License 


\title{
Biophysical and structural studies reveal marginal
}

stability of Acyl ACP Reductase: a crucial hydrocarbon

\author{
biosynthetic enzyme
}

Ashima Sharma ${ }^{1,2}$, Tabinda Shakeel ${ }^{1,2}$, Mayank Gupta ${ }^{1,2}$, Girish H.

Rajacharya $^{1,2}$, Syed Shams Yazdani ${ }^{1,2 *}$

${ }^{1}$ Microbial Engineering Group, International Centre for Genetic Engineering and Biotechnology, New Delhi, India

${ }^{2}$ DBT-ICGEB Centre for Advanced Bioenergy Research, International Centre for Genetic Engineering and Biotechnology, New Delhi, India

*Corresponding Author: Syed Shams Yazdani

Email: shams@icgeb.res.in 


\begin{abstract}
Background: Acyl-ACP reductase (AAR) is one of the two key cyanobacterial enzymes along with aldehyde deformylating oxygenase (ADO) involved in synthesis of long-chain alkanes, a drop-in biofuel. The enzyme is prone to aggregation when expressed in E. coli, leading to varying alkane levels. Intriguingly, the structural characterization remains largely elusive as AAR alone failed to form stable crystals, possibly due to a number of intrinsically flexible random regions. The present work attempts to fill a gap in the literature by investigating the crucial structural aspects of AAR protein associated with its stability and folding.
\end{abstract}

Results: The AAR protein was recombinant expressed in E. coli and purified by metal affinity and gel filtration chromatography. Characterization by dynamic light scattering experiment revealed that recombinantly expressed AAR in E. coli existed in multiple-sized protein particles in the range of 36.4 to $51.6 \mathrm{~nm}$. Intact mass spectrometry revealed that recombinant AAR was heterogenous due to diverse lipidation and de-lipidation resulted in a single mass peak of $40296.87 \mathrm{Da}$ as predicted. Interestingly, while thermal- and urea-based denaturation of AAR showed 2-state unfolding transition in circular dichroism and intrinsic fluorescent spectroscopy, the unfolding process of AAR was a 3-state pathway in $\mathrm{GdnHCl}$ solution. Lower concentration of $\mathrm{GdnHCl}$ appeared to be stabilizing the protein, suggesting that the protein milieu plays a significant role in dictating it's folding. Standard free energy $\left(\Delta \mathrm{G}^{\mathrm{H}_{2} \mathrm{O}} \mathrm{NU}\right)$ of $\sim 4.5 \mathrm{kcal} / \mathrm{mol}$ for steady-state unfolding of AAR indicated borderline stability of the protein. Molecular dynamics simulation conducted on AAR structure in presence of $\mathrm{KCl}$, an ionic solvent with similar properties as $\mathrm{GdnHCl}$ at lower concentrations, suggested that $\mathrm{KCl}$ mediates structural stabilization especially at the concentration of $375 \mathrm{mM}$, and thus was responsible for enhancing its activity. $\mathrm{KCl}$ presence also resulted in 
regional alteration towards the binding site of its neighbouring pathway enzyme, ADO, thus paving the way for coordinated catalysis.

Conclusion: Based on these evidences, we propose that the marginal stability of AAR are plausible contributing reasons for aggregation propensity and hence low catalytic activity of the enzyme when expressed in E. coli for biofuel production. Our results show path for building superior biocatalyst for higher biofuel production.

Keywords: Acyl-ACP reductase, alkane, protein stability, CD spectroscopy, intrinsic fluorescence spectroscopy 


\section{Background}

The emerging unavailability of fossil fuels, heightened levels of pollutants, and greenhouse gas emissions have directed attention towards the development of safe and renewable energy sources $[1,2]$. Biofuels have the potential to provide a sustainable cost-effective alternative for petroleumbased hydrocarbons. High energy density and compatibility of the long-chain alk(a/e)ne with the existing engines and infrastructure furthers its demand as an effective and ideal candidate for dropin biofuels $[2,3]$.

Numerous reports are available showing ability of various microorganisms, primarily cyanobacteria, to produce long-chain alk(a/e)nes from fatty acid precursors [4-9]. Cyanobacterial alkane producing pathway consists of two slow-acting, water-soluble enzymes, namely Acyl-ACP reductase (AAR) (UniProtKB Q54765) and aldehyde deformylating oxygenase (ADO) (UniProtKB Q54764) [10]. AAR catalyzes NADPH- dependent reduction of fatty acyl ACP/CoA to aldehydes which then get converted into one carbon less $\left(\mathrm{C}_{\mathrm{n}-1}\right)$ alkanes by ADO [10-12]. To date, only $\sim 34 \%(425 \mathrm{mg} / \mathrm{L})$ of the maximum theoretical alkane level and $2.5 \mathrm{~g} / \mathrm{L}$ alkane during fed-batch fermentation have been achieved in the $E$. coli host which is still incompetent for use at commercial scale [8]. One of the bottlenecks associated is the low catalytic efficiency of the enzymes involved [11-13].

AAR is a key enzyme of the pathway and is prone to aggregation and the majority of protein forms inclusion bodies when expressed in E. coli [14]. Interestingly, the alkane level varies among different cyanobacteria strains with variable soluble AAR levels [14]. AAR has been reported recently to contain three flexible regions possessing intrinsic flexibility in the N-terminal and middomain of the structure (Fig. 1A) [15]. AAR consists of three domains: the N-terminal domain (NTD, residues 1-130), the middle domain (mid-domain, residues 131-264) with a conserved 
dinucleotide recognition loop for NADPH binding, and the C- terminal domain (CTD, residues 265-341) [15]. Residue C294, which is strictly conserved in AAR homologs, is located at the center of the AAR molecule [15].

Studies have been carried out exploring the functional characterization of AAR and gaining structural insights into the mechanistic aspects of AAR-ADO function $[10,12,14,15]$. However, gaining deep insights into the structural aspects of the AAR protein remains largely elusive. Proper folding, conformation, and stability are very crucial factors to form functionally active AAR protein. Reports are available where ADO, the consecutive enzyme in the pathway, has exhibited remarkable enhanced activity upon improvement in the stability of the protein $[2,16]$.

Therefore, it is imperative to understand the stability and folding of the protein, given the immense biosynthetic potential of AAR in industries for hydrocarbon production. However, so far there are no reports available regarding the conformational and thermodynamics stability characterization of AAR, which are among the major goals for industrially relevant proteins that are likely to be exposed to extreme conditions such as high temperature, presence of co-solvents, low $\mathrm{pH}$, etc.

The stability of a native protein is a function of surrounding environmental variables such as $\mathrm{pH}$, temperature, ionic strength, and solvent composition as they perturb various intramolecular bonds, responsible for stability and integration of the protein. In addition, only perfectly folded proteins survive for long term in biologically crowded environment and interact selectively with their natural ligands. Failure to fold into the intended conformation usually produces inactive and misfolded proteins with undesirable properties. For proteins of biotechnological significance like AAR, understanding of environmental factors that dictate stability and folding will be important for better production of the functional recombinant enzyme at industrial scale. 
In the present study, we purified the heterologously expressed AAR in E. coli and performed detailed in vitro physico-chemical characterization of AAR to gain insights into elucidating the thermodynamic parameters and conformational stability of the protein. We studied the equilibrium unfolding pathway of AAR by carrying out chemical denaturant-, and heat- mediated unfolding experiments, and the unfolding data was used for the calculation of thermodynamic stability parameters associated with the processes. The changes in the secondary and tertiary structural folds were measured by $\mathrm{CD}$ and intrinsic fluorescence-based spectroscopic methods. Unfolding transition behaviour along with the parameters like melting temperature $\left(\mathrm{T}_{\mathrm{m}}\right)$, mid-point of the unfolding transition $\left(\mathrm{D}_{\mathrm{m}}\right)$ and the standard free energy change parameters $\left(\Delta \mathrm{G}^{\mathrm{H}}{ }_{2} \mathrm{O}_{\mathrm{NU}}\right)$ were further elucidated for the AAR protein. These data were indicative of the marginal stability of the AAR protein which is a plausible reason for the aggregation propensity, low turnover number and hence low catalytic activity of the enzyme when expressed in E. coli. Furthermore, molecular dynamics (MD) simulation conducted on AAR structure enabled us to understand the positive effect of ionic solvent $\mathrm{KCl}$ on protein structure stabilization.

\section{Results}

\section{Expression, purification and functional characterization of AAR}

For overexpressing AAR, the codon-optimized aar gene was cloned into the bacterial expression vector pQE30 [8], transformed into M15 strain of E. coli, and induced in liquid culture using 1 mM IPTG. The induced culture was shifted to $18{ }^{\circ} \mathrm{C}$ and cells were harvested after $16 \mathrm{~h}$ of postinduction. SDS-PAGE analysis of the induced culture pellet revealed an intense band around 38 $\mathrm{kDa}$, which was consistent with the calculated molecular mass of AAR and was absent in the uninduced cells (Fig. 1B). 
The purification of 6-His-tagged AAR was carried out in a two-step manner (Fig. 1B). The first step of purification involved Ni-NTA based affinity chromatography, where major contaminant proteins in the supernatant were removed. The employment of the second step, i.e. gel filtration chromatography, helped in the removal of the residual non-AAR proteins (Fig. S1) and the purified AAR fractions were pooled, concentrated and analyzed by SDS-PAGE (Fig. 1B). The results suggest that AAR has been successfully purified by the two steps of chromatographic purification.

Functional AAR is known to exhibit reductase activity catalyzing the acyl-CoA/ACP substrate to its corresponding aldehyde. We checked the activity of the purified AAR using palmitoyl-CoA and NADPH as substrates and analyzed the products of the reaction at different time intervals by GC-MS (Fig. 2). The maximum product concentration peak with retention time 13.9 min, corresponding to $4.7 \mu \mathrm{g} / \mathrm{mL}$ hexadecanal, was achieved at $4 \mathrm{~h}$ of incubation period (Fig. $2 \mathrm{~A}$ and 2B), as analyzed by GC-MS profile (Fig. 2C). The result suggests that the purified AAR is a functionally active protein.

\section{Determination of disperse nature of purified AAR}

We realized from the GFC profile that AAR eluted at wide elution volume rather than a sharp peak (Fig. S1). To understand the nature of AAR eluted at different retention time, we determined its dispersity via dynamic light scattering (DLS) experiment. AAR GFC elutes were divided into four different fractions, namely a, b, c, d (Fig. S1), pooled and concentrated to $\sim 1 \mathrm{mg} / \mathrm{mL}$ for performing DLS. It was observed that $\mathrm{a}, \mathrm{b}$, and $\mathrm{c}$ fractions were monodisperse with varying hydrodynamic diameter of $51.6 \mathrm{~nm}, 45.3 \mathrm{~nm}, 36.4 \mathrm{~nm}$, respectively (Fig. 3). On the other hand, Fraction $\mathrm{d}$ was polydisperse in nature. Fraction $\mathrm{a}, \mathrm{b}$, and $\mathrm{c}$ corresponds to the molecular weight of AAR when analyzed on SDS-PAGE (Fig. S1) and exhibits enzymatic activity (Fig. 2). Together when pooled, fractions $a, b$, and c corresponds to a polydisperse state of solution (Fig. S2). It is 
indicative of multiple-sized protein particles that exist in AAR purified solution as depicted from the GFC profile of AAR as well (Fig. S1), thus corresponding to different states of AAR.

\section{Analysis of intact nature of AAR using LC-Mass Spectrometry}

Native protein intact mass determination of purified AAR was carried out using ESI-mass spectrometry coupled to UHPLC for the upfront separation system. Fig. 4A represents the deconvoluted mass spectrum of AAR derived from the full ESI-MS m/z scan (inset). Purified AAR appeared to adopt heterogeneous states in the solution with mass ranging from 20 to $100 \mathrm{kDa}$ (Fig. 4A), which was in agreement with the DLS data (Fig. 3). Interestingly, when purified AAR was subjected to de-lipidation using Shimadzu MAYI-ODS column prior to LC-ESI MS analysis, it resulted in a single mass peak of $40296.87 \mathrm{Da}$ (Fig 4B). The mass corresponded to the single monomeric molecular weight of AAR and no heterogeneous states could be observed in the deconvoluted spectra (Fig. 4B) as compared to the un-treated AAR (Fig. 4A). This result suggested that some lipid molecules bind to AAR during its heterologous expression in E. coli.

To further explore the nature of lipid molecule bound to AAR, we carried out the LC-MS analysis of the lipid extract from the ODS column (Fig. S3). The characterization of the lipids binding to AAR protein was qualitative in nature by using a non-targeted profiling method. LC-MS

fragmentation data was searched across the database LipidSearch ${ }^{\mathrm{TM}}$ (version 4.1.16, Thermo Fischer Scientific, Copyright (C) 2010-2013 by Mitsui Knowledge Industry, University of Tokyo, Ryo Taguchi) and resulted in list of proposed lipid moieties binding to the AAR as shown in Table S1. The most prominent of these were fatty acids, hydroxy fatty acids, and prenol lipid.

\section{Determination of structural integrity of AAR}


The secondary structure of AAR was determined by monitoring far-UV CD spectra from wavelength 200 to $250 \mathrm{~nm}$ as shown in Fig. 5A. The CD spectra were used for the calculation of the percentage of the helix, sheets, turns, and random structure for AAR protein. The percentage of helix, sheet, turns, and random structures were approximately $39.1 \%, 22.1 \%, 9.7 \%$, and $28.1 \%$, respectively, by using Yang's reference software. The result was in agreement with the reported secondary structure composition of AAR [15] indicating that the purified protein has retained its native secondary structural folds. Intrinsic emission fluorescence of the aromatic acid residues in a protein was exploited for determining nature of the tertiary structural folds of the AAR protein by fluorescence spectroscopy. AAR comprises six tyrosine and six tryptophan residues. The protein was excited at $280 \mathrm{~nm}$ and $295 \mathrm{~nm}$ to obtain intrinsic 'Tyr+Trp' and intrinsic 'Trp' fluorescence spectra, respectively (Fig. 5B and 5C). The emission maximum wavelength $\left(\lambda_{\max }\right)$ of AAR when excited at $280 \mathrm{~nm}$ and $295 \mathrm{~nm}$ spectra was 337 and $340 \mathrm{~nm}$, respectively (Fig. 5B and 5C). The $\lambda_{\max }$ values correspond to the emission of Trp residue when not exposed to the polar solvent environment, indicative of buried residues in a hydrophobic environment which is the characteristic of a folded protein. These results, therefore, suggested that purified AAR existed in its correctly folded native form.

\section{Thermal unfolding and refolding studies of AAR}

The surrounding environment, to which a protein is being subjected to, plays a crucial role in dictating its folding and stability in the cellular condition. Exposure of protein to unfavorable conditions accounts for its misfolding or unfolding leading to aggregation. To understand the effect of one of the critical environmental variables like temperature on the structural integrity of the AAR protein, we have carried out thermal-induced unfolding and refolding studies.

Study of thermal unfolding and refolding of AAR by CD spectroscopy 
Thermal unfolding and refolding of AAR was probed by CD spectroscopy. Fig. 6A represents changes in the CD spectra of AAR when subjected to different temperatures corresponding to the changes in the secondary structure of the protein. The unfolding transition of AAR was monitored at $222 \mathrm{~nm}$ upon subjecting to temperature range varying from $20^{\circ} \mathrm{C}$ to $90{ }^{\circ} \mathrm{C}$ (Fig. 6A). With AAR being subjected to an end denaturation temperature of $90^{\circ} \mathrm{C}$, the loss of secondary structure could be observed. A typical sigmoidal curve was obtained with increasing temperature indicative of almost complete unfolding of protein and loss of its secondary structure (Fig. 6B). The curve also suggested that the secondary structure of AAR remained intact up to $35^{\circ} \mathrm{C}$, with eventual conformational change occurring till $60^{\circ} \mathrm{C}$ followed by the continuous loss of secondary structure at higher temperatures. The melting temperature of AAR was determined by fitting the thermal denaturation transition curve to a two-state model and was found to be $43.3 \pm 0.9{ }^{\circ} \mathrm{C}$ (Table 1). The experimental data fitting coincided with the theoretical data fitting line for the two-state (Fig. 6B). The $90{ }^{\circ} \mathrm{C}$ heat-denatured protein when cooled gradually from $90{ }^{\circ} \mathrm{C}$ to $20^{\circ} \mathrm{C}$ was unable to attain the folded native conformation (Fig 6B). This shows the process is irreversible in nature as depicted.

Thermal unfolding and refolding of AAR probed by intrinsic fluorescence spectroscopy

Changes in the tertiary structure of AAR with increasing temperature was also monitored by recording changes in intrinsic tryptophan fluorescence intensity with continuous scan from 20-90 ${ }^{\circ} \mathrm{C}$ (Fig. 6C and 6D). A continuous decrease in the fluorescence intensity could be observed with increasing temperature (Fig. 6C). The relative fluorescence intensity corresponding to the respective temperature was plotted. The tertiary structure of AAR was retained until $30{ }^{\circ} \mathrm{C}$ as no change in the emission maximum was observed (Fig. 6D). This was followed by a gradual redshift in the $\lambda_{\max }$ from 340 to $344 \mathrm{~nm}$ up to $60^{\circ} \mathrm{C}$ indicating the conformational changes in the 
protein and further leading to denaturation at higher temperatures (Fig. 6C). Similar to CD, fluorescence data was also fitted to a two-state model and fitting parameters obtained were useful in determination of the melting temperature of AAR to be $42.8 \pm 2.1{ }^{\circ} \mathrm{C}$ (Table 1).

Table 1. Melting temperature $\left(\mathrm{T}_{\mathrm{m}}\right)$ of AAR from thermal unfolding transition using different probes

\begin{tabular}{|c|l|c|}
\hline S.No. & \multicolumn{1}{|c|}{ Probe } & Melting temperature $\left.\left(\mathbf{T}_{\mathbf{m}}\right) \mathbf{(}^{\circ} \mathbf{C}\right)$ \\
\hline 1 & CD spectroscopy & $43.3 \pm 0.9$ \\
\hline 2 & Intrinsic fluorescence spectroscopy & $42.8 \pm 2.1$ \\
\hline
\end{tabular}

\section{Denaturant-mediated equilibrium unfolding of AAR}

To comprehend the nature of interactions mainly responsible for stabilizing the AAR protein, effect of different solvent composition on the structural integrity of the protein was studied via chemical denaturant-mediated equilibrium unfolding studies. AAR was subjected to two different denaturants exhibiting different chemical characteristics, namely urea and $\mathrm{GdnHCl}$, and the effect on the conformation and stability of the protein was studied.

\section{Urea-mediated equilibrium unfolding of AAR probed by CD spectroscopy}

The changes in ellipticity at $210-250 \mathrm{~nm}$ were measured at different urea concentrations from $(0-$ $8 \mathrm{M}$ ) (Fig. 7A). The MRE (molar residue ellipticity) values calculated at $222 \mathrm{~nm}$ for each sample were plotted against the respective urea concentration from 0 to $8 \mathrm{M}$ to obtain an unfolding transition curve (Fig. 7B). An increased negative MRE value at lower urea concentration (0.1- 2.5 
M) as compared to native protein, suggests exposure of secondary structure from the compact 3D structure on mild treatment with a denaturant. Beyond 2.5 $\mathrm{M}$ concentration, a decrease in the value of negative MRE suggests a continuous loss of secondary structure till $6.0 \mathrm{M}$ urea concentration. Eventually, at 6.0 M urea concentration, the maximum unfolded fraction of protein was obtained which indicated a complete loss of the secondary structure of the protein (Fig. 7A and 7B). The unfolding transition curve was fitted into the two-state transition model (Equation 6), and the $\mathrm{D}_{\mathrm{m}}$ value (denaturant concentration at which $50 \%$ of the protein is unfolded) was calculated to be $4.3 \pm 0.4 \mathrm{M}$. The standard free energy change was also calculated and found to be $4.3 \pm 1.0 \mathrm{kcal} \mathrm{mol}^{-1}$ respectively (Table 2 ). The urea-induced unfolding of AAR can be represented by the following scheme:

Native $(\mathrm{N}) \rightarrow$ Unfolded state $(\mathrm{U})$

Table 2. Urea-induced equilibrium unfolding parameters of AAR

\begin{tabular}{|c|l|c|c|c|}
\hline S.No. & \multicolumn{1}{|c|}{ Probe } & $\mathbf{D}_{\mathbf{m}}(\mathbf{M})$ & $\begin{array}{c}\mathbf{m}_{\mathbf{N U}} \\
(\mathbf{k c a l} / \mathbf{m o l ~ M})\end{array}$ & $\begin{array}{c}\text { Standard free energy change } \\
\mathbf{( k c a l ~ m o l}^{\mathbf{1}} \mathbf{)}\end{array}$ \\
\hline 1 & CD spectroscopy & $4.3 \pm 0.4$ & $0.8 \pm 0.24$ & $4.32 \pm 1.0$ \\
\hline 2 & Intrinsic & $3.9 \pm 0.2$ & $1.5 \pm 0.63$ & $5.45 \pm 0.9$ \\
& fluorescence & & & \\
\hline
\end{tabular}

Urea-mediated equilibrium unfolding of AAR probed by intrinsic fluorescence spectroscopy

The change in fluorescence emission intensity at $340 \mathrm{~nm}$ and $\lambda_{\max }$ in the presence of increasing concentration of urea for AAR protein have been shown in Fig. 7C and 7D. It was observed that the fluorescence intensity of AAR was higher in the presence of lower concentrations of urea 
which further increased to the maximum value at $2.5 \mathrm{M}$ with unaltered $\lambda_{\max }(340 \mathrm{~nm})$ of emission. These initial changes in fluorescence intensity without affecting $\lambda_{\max }$ are readily observed at low urea concentrations and could be a result of environmental alteration around the quenched tryptophan residues in the fully folded protein. The fluorescence intensity started decreasing beyond $2.5 \mathrm{M}$ with the gradual redshift in the $\lambda_{\max }$ representing the onset of the structure unfolding. A significant decrement in the fluorescence intensity and an appreciable redshift in the $\lambda_{\max }(357$ $\mathrm{nm}$ ) was observed at 5.5 $\mathrm{M}$ with no further apparent changes (Fig. 7D), representing the exposure of aromatic amino acid residues to the environment and complete loss of AAR tertiary structure. The unfolding transition curve was fitted into the two-state transition model (Equation 6) (Fig. 7D). The $\mathrm{D}_{\mathrm{m}}$ value from the model was calculated to be $4.7 \pm 0.2 \mathrm{M}$ and the standard free energy change was calculated to be $5.4 \pm 0.9 \mathrm{kcal} \mathrm{mol}^{-1}$ (Table 2). The results obtained here further validate the earlier-calculated parameters from the $\mathrm{CD}$ data.

\section{GdnHCl-mediated equilibrium unfolding of AAR probed by CD spectroscopy}

The far-UV CD spectra of AAR in the presence of different $\mathrm{GdnHCl}$ concentrations have been presented in Fig. 8A. A three-step change of CD signal at $222 \mathrm{~nm}$ was observed with increasing concentrations of $\mathrm{GdnHCl}$ (Fig. 8B). The first transition occurred from 0 and $1.25 \mathrm{M} \mathrm{GdnHCl}$ and was followed by an increase of CD signal from 1.25 to $2.25 \mathrm{M}$ and complete unfolding occurred over 3.0 M GdnHCl (Fig. 8B). The CD signal at $222 \mathrm{~nm}$ was lost during the first transition, indicating partial unfolding of AAR molecules at lower denaturant concentrations. However, the $\mathrm{CD}$ signal at $222 \mathrm{~nm}$ increased again during the second transition with a further increase of $\mathrm{GdnHCl}$ concentration, regaining approximately $60 \%$ of the native secondary structure. Then, a complete loss of secondary structure occurred during the third transition, showing that AAR adopted a complete unfolded state. The result obtained indicates that the AAR had undergone 
GdnHCl-mediated complete unfolding via intermediate formation thus following the 3-state folding transition. The unfolding transition curve was fitted into the three-state protein folding model (Equation 11). The $\mathrm{D}_{\mathrm{m}}(\mathrm{NI})$, $\mathrm{Dm}(\mathrm{NU})$ were determined to be $1.7 \pm 0.05 \mathrm{M}$ and $3.1 \pm 0.3 \mathrm{M}$ respectively (Table 3). Standard free energy of unfolding of the transitions from native to

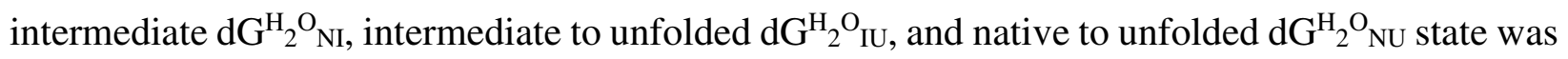
determined to be $1.5 \pm 0.1 \mathrm{kcal} \mathrm{mol}^{-1}, 2.8 \pm 0.5 \mathrm{kcal} \mathrm{mol}^{-1}$, and $4.3 \pm 0.5 \mathrm{kcal} \mathrm{mol}^{-1}$, respectively (Table 3).Therefore, GdnHCl-induced unfolding can be represented by the following scheme:

Native $(\mathrm{N}) \rightarrow$ Intermediate state (I) $\rightarrow$ Unfolded state (U)

\section{GdnHCl-mediated equilibrium unfolding of AAR probed by intrinsic fluorescence spectroscopy}

The AAR unfolding transition was monitored at different $\mathrm{GdnHCl}$ concentrations through the changes of fluorescence intensity and the emission maximum wavelength $\left(\lambda_{\max }\right)$. Fig. $8 \mathrm{C}$ showed the fluorescence spectra and fluorescence intensity of AAR at different $\mathrm{GdnHCl}$ concentration, and Fig. $8 \mathrm{D}$ showed the changes in the $\lambda_{\max }$ of AAR in the presence of increasing $\mathrm{GdnHCl}$ concentrations. We observed the initial decrease in the fluorescence intensity of AAR with consistent $\lambda_{\max }$ at a low concentration of the denaturant, indicating the protein native structure is not altered. The unfolding induced by $\mathrm{GdnHCl}$ exhibited two transition processes. During the first transition, there was an increase in fluorescence intensity and a redshift in the $\lambda_{\max }$ as the concentration of $\mathrm{GdnHCl}$ increased from 1.0 to $2.25 \mathrm{M}$. These changes indicated the formation of an intermediate which had a fluorescence quantum yield similar to the native AAR. The fluorescence spectrum of this intermediate was slightly red-shifted, suggesting that the Trp residues' environments were not appreciably altered. During the second transition, further denaturation process was accompanied by a decrease in the fluorescence intensity and a significant red-shift in the $\lambda_{\max }$. The spectra showed a clear decrease in fluorescence intensity and a further 
red-shift from $345 \mathrm{~nm}$ to $360 \mathrm{~nm}$ was observed as the $\mathrm{GdnHCl}$ concentration was increased from 2.25 M to 3.0 M. However, no further apparent changes were observed both in fluorescence emission maximum peak and intensity with increasing of $\mathrm{GdnHCl}$ concentration. This fluorescence redshift indicated that the Trp residues were more exposed to a polar environment because of the complete unfolding of AAR at higher $\mathrm{GdnHCl}$ concentration. The unfolding transition curve was fitted into the three-state transition model (Equation 11), and the $\mathrm{Dm}_{\mathrm{m}}(\mathrm{NI})$ and Dm (NU) were determined to be 1.6 $\pm 0.2 \mathrm{M}$ and 2.6 $\pm 0.1 \mathrm{M}$, respectively (Table 3). Standard free energy of unfolding of the transitions from native to intermediate $\mathrm{dG}^{\mathrm{H}}{ }_{2} \mathrm{O}_{\mathrm{NI}}$, intermediate to unfolded $\mathrm{dG}_{2}^{\mathrm{H}_{2}}{ }_{\mathrm{IU}}$, and native to unfolded $\mathrm{dG}^{\mathrm{H}}{ }_{2} \mathrm{NU}_{\text {NU }}$ state was determined to be $1.4 \pm 0.1 \mathrm{kcal} \mathrm{mol}^{-}$ 1, $3.3 \pm 0.4 \mathrm{kcal} \mathrm{mol}^{-1}$, and $4.7 \pm 0.5 \mathrm{kcal} \mathrm{mol}^{-1}$, respectively (Table 3 ). The results obtained were in agreement with the $\mathrm{CD}$ data showing that $\mathrm{AAR}$ follows a 3-state $\mathrm{GdnHCl}$-mediated unfolding transition via intermediate formation. From the theoretical curves, the apparent fraction of native $\left(\mathrm{f}_{\mathrm{N}}\right)$, intermediate $\left(\mathrm{f}_{\mathrm{I}}\right)$ and unfolded (fu) protein with respect to denaturant concentration calculated by using Equation 9 (Fig. 8e). The maximum fractional population ( 60\%) of intermediate state for the protein was observed at $2.25 \mathrm{M} \mathrm{GdnHCl}$ concentration.

Table 3. GdnHCl-mediated equilibrium unfolding parameters of AAR

\begin{tabular}{|l|l|l|l|l|l|l|l|l|}
\hline Probe & $\mathrm{D}_{\mathrm{m} \text { NI }}(\mathrm{M})$ & $\mathrm{D}_{\mathrm{m} \mathrm{NU}}$ & $\mathrm{dG}_{2}{ }_{2}{ }_{\mathrm{NI}}$ & $\mathrm{dG}_{2}{ }^{\mathrm{O}}{ }_{\mathrm{NU}}$ & $\mathrm{dG}_{2} \mathrm{H}_{\mathrm{IU}}$ & $\mathrm{m}_{\mathrm{NI}}$ & $\mathrm{m}_{\mathrm{NU}}$ & $\mathrm{m}_{\mathrm{IU}}$ \\
& & $(\mathrm{M})$ & $(\mathrm{kcal} / \mathrm{mol})$ & $(\mathrm{kcal} / \mathrm{mol})$ & $(\mathrm{kcal} / \mathrm{mol})$ & $(\mathrm{kcal} / \mathrm{mol}$ & $(\mathrm{kcal} / \mathrm{mol}$ & $(\mathrm{kcal} /$ \\
$\mathrm{CD}$ & $1.7 \pm 0.05$ & $3.1 \pm 0.3$ & $1.5 \pm 0.1$ & $4.3 \pm 0.5$ & $2.8 \pm 0.5$ & $0.9 \pm 0.1$ & $1.4 \pm 0.3$ & $0.5 \pm 0.3$ \\
\hline $\begin{array}{l}\text { Fluores } \\
\text { cence }\end{array}$ & $1.6 \pm 0.2$ & $2.6 \pm 0.1$ & $1.4 \pm 0.1$ & $4.7 \pm 0.5$ & $3.3 \pm 0.4$ & $0.8 \pm 0.7$ & $1.7 \pm 0.5$ & $0.9 \pm 0.2$ \\
\hline
\end{tabular}




\section{Computational evaluation of AAR stability and interactions in presence of $\mathrm{KCl}$}

$\mathrm{KCl}$, an ionic solvent with similar properties as $\mathrm{GdnHCl}$ at lower concentrations, has been reported to enhance AAR activity significantly $[11,15]$ After an extensive biophysical characterization of AAR exhibiting different unfolding properties in presence of different solvent environments, we wanted to understand the effect of $\mathrm{KCl}$ using computational modelling and simulation methods. As presence of an intermediate of AAR at lower concentration of ionic solvent has been observed in the present study, we were inquisitive to understand the effect of $\mathrm{KCl}$ on structure and stability of AAR.

Molecular dynamics simulations of AAR (PDB ID: 6JZU) in solution with varying concentrations of $\mathrm{KCl}$ were carried out. Simulations of the enzyme in each representative state enabled us to directly examine the effects of $\mathrm{KCl}$ on protein dynamics. The energy decomposition of the AAR under different simulation environment $(0-1000 \mathrm{mM} \mathrm{KCl})$ at two different temperatures $298 \mathrm{~K}$ and $303 \mathrm{~K}$ is shown in Fig. 9A. AAR with increasing concentration of $\mathrm{KCl}$ seemed to attain more energetically favored state, especially at $375 \mathrm{mM}$ conc. of $\mathrm{KCl}$. For each simulation, the root-mean square deviations (RMSD) with reference to initial structure used in simulations of the protein were calculated (Fig. S4A). Our results show that the proteins were mostly stable and reached geometrical convergence after $500 \mathrm{~ns}$ timescale at different applied conditions.

Afterward, to identify the regions of the protein exhibiting differences in the fluctuations, RMSD of the protein (backbone) was calculated for the protein by extracting 100 snapshots at 2 ns intervals from the last $200 \mathrm{~ns}$ of the whole MD trajectories and then aligning each one of them with the first frame of the extracted frames at different concentrations of $\mathrm{KCl}(0$ and $375 \mathrm{mM}$ of $\mathrm{KCl}$ ) (Fig. S4b). The enzymes were colored on the basis of the level of fluctuations observed, where blue and red represent the lowest and highest fluctuations, respectively, at $0 \mathrm{M}$ and $375 \mathrm{mM}$ 
of $\mathrm{KCl}$ (Fig. 9B and 9C). Overall shape of the AAR protein was observed to be compactly packed in presence of $375 \mathrm{mM}$ of $\mathrm{KCl}$. Additionally, comparing the regions of highest fluctuations of AAR protein at $0 \mathrm{M}$ and $375 \mathrm{mM}$ of $\mathrm{KCl}$, we observed differences primarily in the $\mathrm{N}$-terminal domain (R2, R3, R5, and R6) and mid domain regions of the protein (R1, R4) as represented in Fig. 9B and Fig. 9C.

Residues in the regions R2 (L69-R72), R3 (L114-E123), R5 (A14-D16), and R6 (D28-S35) demonstrated increased fluctuation when AAR was exposed to $375 \mathrm{mM}$ of $\mathrm{KCl}$. All these regions belonged to N-terminal domain of AAR where the binding of next enzyme in the pathway, i.e., ADO, was observed earlier [15]. Residues in the region R1 (A223-V230) on the other hand exhibited higher fluctuation in absence of $\mathrm{KCl}$. $\mathrm{R} 1$ region belongs to the intrinsic flexible region III of the mid domain of AAR and in the presence of $375 \mathrm{mM}$ of $\mathrm{KCl}$ diminished RMSF values were observed.

The surface view of the cluster representative of AAR under subjected conditions (Fig. 9D and 9E) clearly represented the differences in the structure of AAR as represented by the marked regions in the presence and absence of $\mathrm{KCl}$ in the solvent environment. Interestingly, a more compact structure with major structural changes in the N-terminal regions of AAR associated with binding to $\mathrm{ADO}$ protein was observed in presence of $\mathrm{KCl}$ salt as compared to the control.

\section{Discussion}

Schirmer group in 2010 had identified two enzymes of the alkane biosynthetic enzyme pathway [10]. Since then, extensive structural characterization of the terminal ADO protein and its variants had been carried out [2]. Surprisingly for AAR, the structural aspects still remain largely obscure 
generating a wide gap in the literature. The matter becomes crucial to be investigated considering the colossal biotechnological relevance of the protein and diminishingly existing structural information.

In the present communication, we have attempted to isolate and carry out a detailed characterization of the AAR protein. The AAR protein from Synechococcus elongatus PCC7942 had been reported to exhibit the maximum activity among other cyanobacterial AARs [14]. We studied the expression of this protein in E. coli since the maximum achieved hydrocarbon production to date has been reported in this host [8]. However, AAR, a water-soluble cyanobacterial enzyme, unlike ADO is prone to aggregation when expressed recombinantly in the heterologous host. The present work has successfully attempted to investigate the reasons associated with the structural discrepancies exhibited by AAR and shortlisted the probable bottlenecks associated with its aggregation which could be targeted and resolved for achieving improved hydrocarbon production.

AAR protein has been expressed and successfully purified from the E. coli host (Fig. 1). The enzyme has exhibited reductase activity thus confirming that the purified AAR is a functionally active protein (Fig. 2). Interestingly, GFC elution profile of AAR does not correspond to a monomeric fraction, instead, a broadly distributed peak-like pattern has been observed indicative of the co-existence of multiple-sized states of the protein in solution (Fig. S1), which was also previously reported by Kudo et al. group [18]. The presence of other protein contaminants was ruled out as only a single band was observed in SDS-PAGE corresponding to the monomeric molecular weight of the AAR protein (Fig. 1 and Fig. S1). The polydispersity of the AAR purified fraction was further established by DLS confirming with varied-sized protein particles in the 
solution (Fig. 3). Although it is difficult to quantify the oligomeric state, the data altogether offers an indication of size spread and relative contributions.

Additionally, mass spectrometry-based intact mass analysis of purified AAR exhibited irregularly distributed multiple states of AAR (Fig. 4a), further confirming the aforementioned results of GFC and DLS data. Excitingly, when the AAR purified fraction was subjected to de-lipidation, a single monomeric state of the protein dominated in the solution (Fig. 4b). The data acquired is intriguing as it suggests fatty acid-binding induces heterogenous multiple-sized states of the AAR protein. Reports are available where fatty acid-binding to a protein induces the oligomerization which can lead to aggregation of the protein [19]. We propose that this could be one of the contributing reasons for enhanced aggregation propensity of the otherwise water-soluble AAR protein [9] when expressed in the E. coli cells for hydrocarbon production. The current study accommodates comprehensive in vitro biophysical characterization of AAR to gain insights into the structural and stability aspects of the protein. It is possible that protein stabilities could be different inside cells than in vitro due to protein-protein interaction and other factors. However, few key experimental studies show that protein stability in cells is approximately the same as deduced in vitro [20-22].

We have used far-UV CD, and intrinsic fluorescence spectroscopy to know about the secondary and tertiary structural folds of AAR protein. The calculated $\%$ of secondary structure from farUV CD spectra were $\sim 40 \%$ helix, $\sim 22 \%$ sheets, $\sim 10 \%$ turns, and $\sim 28 \%$ random coil, which suggested a properly folded secondary structure (Fig. 5) and was in concordance with the recently published structure of AAR [15]. The emission fluorescence spectra of native AAR showed an emission maximum of $340 \mathrm{~nm}$ (Fig. 5). The $\lambda_{\max }$ values obtained (340 nm) corresponded to the emission of six Trp residues and was indicative of slightly exposed buried residues in a hydrophobic environment when not entirely exposed to the polar solvent, which is the 
characteristic of a folded protein. The results are therefore suggestive of purified AAR to exist in its folded native form.

Thermal stability is a critical property for many biotechnological applications of proteins as it implies longer life-times and frequently higher tolerance to the presence of organic co-solvents, extreme $\mathrm{pH}$ values, and high salt concentration or pressures [23]. In the present work, we have reported temperature-induced denaturation and renaturation studies of AAR.

AAR upon thermal denaturation, measured by CD and intrinsic fluoresce spectroscopy (Fig. 6), apparently displays a single transition. The protein resists change in its tertiary and secondary native structure till $30{ }^{\circ} \mathrm{C}$ and $35^{\circ} \mathrm{C}$ respectively, followed by continuing structural transition and complete denaturation beyond $60{ }^{\circ} \mathrm{C}$. The thermal denaturation process of AAR appears to be irreversible in nature (Fig. 6B). Melting temperature $\left(\mathrm{T}_{\mathrm{m}}\right.$, the temperature at which $50 \%$ of the protein is unfolded) of AAR was determined to be $43.3 \pm 0.9{ }^{\circ} \mathrm{C}$ and $42.8 \pm 2.1{ }^{\circ} \mathrm{C}$ by $\mathrm{CD}$ and intrinsic fluorescence spectroscopy, respectively. The thermal unfolding and refolding transition studies signify that the AAR fairly resists the change in structure upon unfolding as indicated by the thermal denaturation transition curve. But once the protein is denatured, it fails to adopt the native structure with a gradual lowering of the temperature thereby leading to irreversible denaturation and inactivation of the protein as demonstrated by the present study.

Interestingly, from this data, it could be inferred that the temperature range up to which AAR resists the change in its native structure is below the E. coli cultivation temperature at which the protein is usually expressed $\left(30-37^{\circ} \mathrm{C}\right)$, thereby undergoing thermal stress. This is suggestive that thermal stress is one of the contributing factors to the aggregation propensity of the protein when expressed in E. coli host. Loss of functional protein occurs due to irreversible degradation or misfolding or denaturation, of the otherwise water-soluble cyanobacterial enzyme, leading to 
aggregation in the heterologous host. Our results, therefore, indicate that there exists an immense scope to improve the thermal stability of the AAR protein so that the protein can withstand thermal stress when expressed in E. coli and end up not forming inclusion bodies.

The chemical stability of AAR protein has also been characterized by carrying out denaturantmediated equilibrium unfolding studies. The unfolding processes of AAR induced by urea and guanidine hydrochloride $(\mathrm{GdnHCl})$ were investigated by spectroscopic methods. In the unfolding processes, AAR tertiary structural transition was monitored by the changes of intrinsic fluorescence emission spectra, and its secondary structural transition was measured by the changes of far-UV CD spectra.

The urea-mediated unfolding of AAR appears to follow a single unfolding transition (Fig. 7). The protein resists the change in the secondary and tertiary structure till $2.5 \mathrm{M}$ urea concentration followed by a gradual loss in the structure of the protein till $6.0 \mathrm{M}$ urea concentration beyond which no further loss in the structure has been observed. The redshift in the emission maximum accompanying the loss of secondary structure indicates protein to attain an unfolded state. AAR undergoes a co-operative two-state unfolding transition between $\mathrm{N}$ (native) and $\mathrm{U}$ (unfolded) state when treated with urea. The $\mathrm{D}_{\mathrm{m}}$ (denaturant concentration at which $50 \%$ of the protein unfolded) and standard free energy was determined to be $\sim 4.0 \mathrm{M}$ and $\sim 5.0 \mathrm{kcal} \mathrm{mol}^{-1}$ respectively (Table 3).

The GdnHCl- induced equilibrium unfolding of AAR appears to follow the double sigmoidal curve indicative of two transitions, one at lower $\mathrm{GdnHCl}$ concentration while another at a concentration of 2.25 M GdnHCl (Fig. 8). The protein becomes fully unfolded at 3.0 M GdnHCl concentration. Due to the presence of more than one kind of observed population in the process, the data were fitted to a three-state model which explains the presence of $\mathrm{N}$ (native), I (intermediate), and $\mathrm{U}$ 
(unfolded) populations in the unfolding process (Fig. 8). Native protein population exists below 2.25 $\mathrm{M} \mathrm{GdnHCl}$ concentration, the intermediate population is largely at the concentration of 2.25 M GdnHCl. From this data, it is reasonable to assume the existence of a three-state mechanism in which an intermediate is populated during the equilibrium unfolding process at $2.25 \mathrm{M}$ concentration of $\mathrm{GdnHCl}$ (Fig. 8E). The percentage of intermediate state at $2.25 \mathrm{M} \mathrm{GdnHCl}$ concentration is about $60 \%$ (Fig. 8E).

Although native AAR showed partial unfolding at initial $\mathrm{GdnHCl}$ concentration, the intermediate state formed at 2.25 M concentration seems to regain nearly native-like secondary structure (CD spectra) (Fig. 8A), similar fluorescence quantum yield and similar fluorescence emission maxima (Fluorescence spectra) (Fig. 8C). This could be attributed to the mode of the unfolding mechanism of $\mathrm{GdnHCl}$ considering that $\mathrm{GdnHCl}$ is a monovalent salt having both ionic and chaotropic effects $[24,25]$.

Guanidine is a salt expected to exist in the fully ionized form in aqueous solutions. The presence of Gdn+ and Cl- influence the overall stability of proteins [24]. The stability of the intermediate is interpreted in terms of stabilization by generated $\mathrm{Gdn}^{+}$and $\mathrm{Cl}^{-}$ions masking the charged moieties of protein thereby reducing or even eliminating any destabilizing electrostatic interactions which has been reported for other enzymes as well [25,26]. Interestingly, AAR has been reported to interact with ADO primarily via electrostatic interactions [15], thus retaining the exposed charged residues on its surface, which in the present case are stabilized at the lower concentration of the $\mathrm{GdnHCl}$ resulting in stabilization of the intermediate state of the protein. Strikingly, it is well established that the presence of $\mathrm{KCl}$ salt augments the AAR activity in a significant manner $[11,15] . \mathrm{KCl}$ is known to exhibit ionic character similar to the low concentration of $\mathrm{GdnHCl}$ [27]. The MD simulation studies revealed the effect of $\mathrm{KCl}$ on the $\mathrm{N}$-terminal domain of AAR, 
responsible for interaction with the ADO protein, and also the diminished fluctuations in the flexible region III was observed when protein was subjected to solvent with $375 \mathrm{mM} \mathrm{KCl} \mathrm{(Fig.} \mathrm{9).}$ The acidic residues of this helix 7 of ADO are known to form strong electrostatic interactions with the basic residues from the long helical region (R73-H91), as well as R118 from flexible region II of AAR [15]. Interestingly a very significant difference in the surface properties of the AAR could be observed in these regions (Fig. 9C) in presence of $\mathrm{KCl}$. The presence of $\mathrm{KCl}$ also energetically favored compact AAR structure as compared to the control (0 M) (Fig. 9A). Based on the present data it can be fairly explained that $\mathrm{KCl}$ stabilizes the AAR structure by masking the exposed electrostatic charge on the protein. The implications can be drawn that KCl-mediated improved activity of AAR is imparted through structural stabilization as reported previously for other enzymes as well [28].

However, at higher concentration of $\mathrm{GdnHCl}$ acts as a classical denaturant leading to the unfolding of AAR protein chain as could be observed beyond 3.0 M concentration of GdnHCl (Fig. 8).

From the data, it could be extracted that though protein appears to resist change in the structure during unfolding till moderate concentration of denaturant interestingly the cooperativeness of the unfolding process is low as indicated by the cooperativity parameter (m) calculated by fitting the data in protein folding equation (Table 3 ). The low value of $\mathrm{m}$ indicates that the unfolding process follows multiple transitions rather than a single cooperative transition [29] which contributes to the marginal stability of the protein. This low cooperativity in unfolding could be attributed to the recently reported intrinsic flexible regions in the AAR protein [15].

AAR undergoes different modes of unfolding transition induced by chaotropic effects of urea and chaotropic as well as ionic effects of GdnHCl. The unfolding of AAR suggests different unfolding pathways and mechanisms for the two denaturants. The protein seems to use different pathways 
for unfolding in different milieu and is a classic example of how the environment dictates the path a protein might take to fold. The knowledge accumulated could be of immense biotechnological significance as well. The following scheme represents the two possible unfolding pathways in $\mathrm{GdnHCl}$ and urea solutions for AAR.

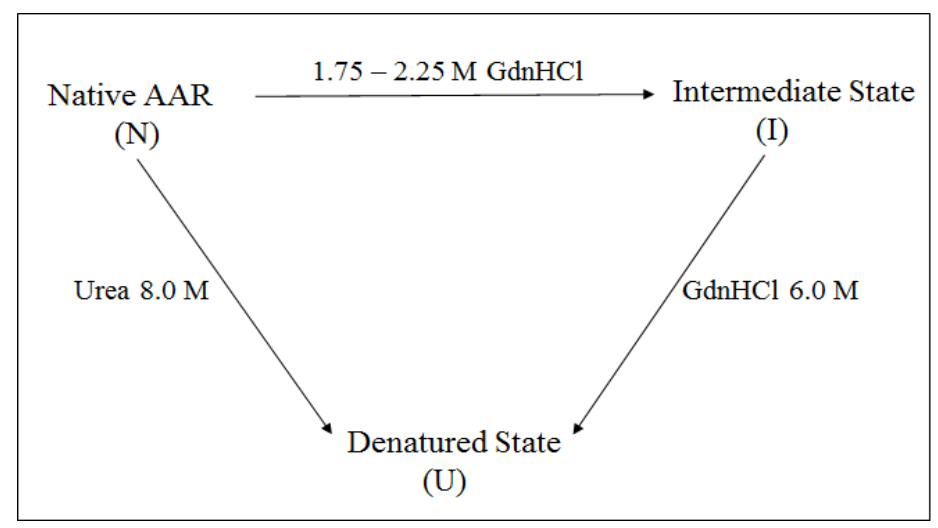

However, the standard free energy deduced from the two processes is similar for AAR and is indicative of the marginal stability of the AAR protein, which is a plausible reason for the low turnover number and hence the low catalytic activity of the enzyme when expressed in E. coli. The present thermodynamic stability studies carried out are quite consistent with the recently published literature where AAR is reported to adopt lose conformation and is composed of three intrinsic flexible regions existing across its $\mathrm{N}$-terminal domain and mid-domain [15] which could be proposed to be contributing to the borderline stability of the enzyme. The work carried out in the present communication thus indicates that there exists a wide scope in improving the stability of this industrially relevant protein which in turn can improve the performance of the enzyme and the hydrocarbon production in the E. coli host.

In the E. coli proteome, it had been found that approximately $15 \%$ of proteins have a free energy change of $\leq 4.0 \mathrm{kcal} / \mathrm{mol}$, while it undergoes an abrupt decrease once the cell is in thermal stress 
[20]. Hence, the above-calculated values of thermodynamic stability parameters for AAR reflect that it is a marginally stable entity (Table 2 and 3), which can be destabilized by applied minimal stress to the cell. The study further proposes that the borderline stability of the AAR protein makes it prone to aggregation when expressed in E. coli cells for hydrocarbon production and in turn affecting the hydrocarbon production level. Hydrocarbon production levels have been reported to fluctuate with varying soluble levels of AAR [14].

This highlights the fact that the AAR protein aggregation could be one of the limitations associated with reduced hydrocarbon production, which in the present study could be correlated with the marginal stability of the protein when expressed in E. coli. Thus, the outcome of the present study involving the unfolding pathways, determination of thermodynamic stability provides us preliminary information about the stability and mechanistic aspects of the unfolding of a key nodal enzyme involved in biosynthetic hydrocarbon production pathway. Taking into consideration the present studies and further careful investigation in the near future, it would certainly provide muchfocused information on improving the stability of the enzyme in question, in turn, to further improve hydrocarbon production.

\section{Conclusion}

The present work investigated the crucial structural aspects of AAR protein associated with its stability and folding, which in-turn reflected on structural integrity of the protein. The protein milieu has been shown to play a significant role in dictating it's folding. Standard free energy $\left(\Delta \mathrm{G}_{2} \mathrm{H}_{\mathrm{NU}}\right)$ elucidated for steady-state unfolding of AAR was indicative of borderline stability of the protein. MD simulation conducted on AAR structure suggested that the ionic solvent $\mathrm{KCl}$ mediates structural stabilization and regional alteration towards the binding site of its neighbouring pathway enzyme aldehyde deformylating oxygenase. Based on these evidences, we propose that 
the marginal stability of AAR are plausible contributing reasons for aggregation propensity and hence low catalytic activity of the enzyme when expressed in E. coli for biofuel production.

\section{Methods}

\section{Expression and purification of AAR}

The M15 strain of E. coli was transformed with the pQE30AAR plasmid containing codon optimized gene encoding AAR from Synechococcus elongatus PCC7942 [8]. The transformed E. coli cells were grown overnight in LB medium (containing $100 \mu \mathrm{g} / \mathrm{mL}$ Ampicillin) at $37^{\circ} \mathrm{C}$ with shaking at $150 \mathrm{rpm}$ to obtain primary culture. The cells were further inoculated from the primary culture into a secondary culture of $1000 \mathrm{~mL}$ of LB medium containing ampicillin $(100 \mu \mathrm{g} / \mathrm{mL})$ and cultured at $37^{\circ} \mathrm{C}$ with shaking at $150 \mathrm{rpm}$. Growth of the cells was monitored and the cells were induced with $1.0 \mathrm{mM}$ of IPTG when the OD600 reached about 0.8. Post induced cells were cultured for 18 hours at $18{ }^{\circ} \mathrm{C}$ with shaking at $150 \mathrm{rpm}$. The cells were subsequently harvested for isolating the expressed AAR protein. A $200 \mu \mathrm{L}$ of cell culture was aliquoted and centrifuged to collect the cell pellet. The cell pellet was resuspended in SDS-PAGE loading buffer, boiled at 95 ${ }^{\circ} \mathrm{C}$, and analyzed on $12 \%$ SDS-PAGE gel to confirm protein expression.

The harvested cells were further lysed by sonication for the preparation of the soluble AAR. After lysis, the cell lysate was centrifuged at $10,000 \mathrm{rpm}$ for one hour at $4{ }^{\circ} \mathrm{C}$. The supernatant obtained was filtered through $0.45 \mu \mathrm{m}$ filter (Millipore) before applying to the chromatography column in FPLC unit (BioRad). AAR was purified by a 2-step method which includes metal affinity chromatography using Ni-NTA resin (Qiagen) and Gel Filtration Chromatography (GFC) using HiLoad 16/600 Superdex 200 prep grade column (GE Life Sciences). Fractions containing AAR 
were identified by SDS-PAGE and were pooled. Protein was stored in $50 \mathrm{mM}$ Tris, $100 \mathrm{mM} \mathrm{NaCl}$, and $1 \mathrm{mM}$ DTT at $\mathrm{pH} 7.4$. The protein concentration was determined using an extinction coefficient of $41940 \mathrm{M}^{-1} \mathrm{~cm}^{-1}$ at $280 \mathrm{~nm}$.

\section{Activity assay of AAR}

In vitro enzyme assay was carried out to determine the activity of the purified AAR. Assay was performed in $50 \mathrm{mM}$ Tris buffer containing $250 \mathrm{mM} \mathrm{KCl}, 2 \mathrm{mM} \mathrm{MgCl}_{2}, 10 \mathrm{mM} \mathrm{DTT}, 1 \mathrm{mg} / \mathrm{mL}$ BSA, $1 \mathrm{mM}$ NADPH, $400 \mu \mathrm{M}$ Palmitoyl CoA, and $5 \mu \mathrm{M}$ AAR at $\mathrm{pH}$ 8.0. The reaction mix was incubated at $37^{\circ} \mathrm{C}$ for different time intervals of 0 to 6 hours, and an equal volume of ethyl acetate was used for the termination of the reaction. The collected sample was then vortexed at high speed for $10 \mathrm{~min}$ and centrifuged. The aqueous phase was analyzed by GC-MS/MS.

\section{Dynamic Light Scattering of AAR}

A different set of GFC-eluted fractions of AAR were pooled and concentrated to achieve $1 \mathrm{mg} / \mathrm{mL}$ concentration of each pooled fraction. Samples were then centrifuged at 10,000 rpm for $30 \mathrm{~min}$ at $4{ }^{\circ} \mathrm{C}$. Light scattering measurements were taken using Zetasizer Nano-ZS (Malvern Instruments) at a light scattering angle of $90^{\circ}$ using $632 \mathrm{~nm}$ laser. All studies were conducted at room temperature. AAR-size distributions were calculated using the Stokes-Einstein relationship carried out with the Malvern Zetasizer ver. 7.12 software.

\section{Mass spectrometry-based characterization of AAR}

LC-MS analysis of AAR protein was performed using Orbitrap Fusion Lumos Tribrid Mass Spectrometer (Thermo Fischer Scientific, Singapore). Ultra-High Pressure Liquid Chromatography (UHPLC) C8 column (Eclipse plus C8, 2.1x150mm, 5 um, P/N 959701-906, USA) coupled to ESI-Mass Spectrometer was used for the intact mass determination of AAR 
protein. $500 \mathrm{ng}$ of AAR (prepared in $10 \mathrm{mM}$ ammonium acetate, $0.1 \%$ formic acid) was injected into the UHPLC- C8 column. Running conditions were as follows: oven temperature $40{ }^{\circ} \mathrm{C}$, eluent flow rate $0.3 \mathrm{ml} / \mathrm{min}$, overall run time $10 \mathrm{~min}$. Protein is eluted using an increasing gradient of acetonitrile, $0.1 \%$ formic acid, and is subjected to ESI-MS. The full ESI-MS (150 to $2000 \mathrm{~m} / \mathrm{z}$, $3500 \mathrm{~V}$, Sheath gas 42 arb, Aux gas flow 10 arb, Sweep gas flow 1 arb, S-lens RF 40, Capillary temp $340^{\circ} \mathrm{C}$ and Aux gas heater temp $360^{\circ} \mathrm{C}$ ) scan was obtained and was deconvoluted using Thermo Scientific ${ }^{\mathrm{TM}}$ Biopharma Finder $^{\mathrm{TM}}$ software with the following set parameters: $\mathrm{m} / \mathrm{z}$ range: 1000-3000, output mass range: 10000 -160000, mass tolerance: $0.04 \mathrm{Da}$, Target mass: $80000 \mathrm{Da}$, Charge state range: 10-100, choice of peak model: Intact Protein. De-lipidation of AAR was carried out using Shimadzu MAYI-ODS column $(5 \mathrm{~mm} \mathrm{~L} \times 2.0 \mathrm{~mm}$ I.D., $50 \mu \mathrm{m})$. AAR protein $(1$ $\mu \mathrm{g}$ ) was injected into the ODS column and eluted using $10 \mathrm{mM}$ ammonium acetate buffer within $1.5 \mathrm{~min}$ of the elution time monitored by UV-280 $\mathrm{nm}$. The flow rate was kept at $0.6 \mathrm{~mL} / \mathrm{min}$ and the column temperature was set at $40{ }^{\circ} \mathrm{C}$. The eluted AAR fraction was collected and further injected into the UHPLC C8 column coupled to ESI-mass spectrometer for intact mass determination. MAYI-ODS trapped lipid fraction was collected using gradient method, mobile phase $\mathrm{A}$ is $10 \mathrm{mM}$ ammonium formate and mobile phase $\mathrm{B}, 2$-propanol. The $\% \mathrm{~B}$ composition was varied as follows: $5 \%(0-1 \mathrm{~min}) \rightarrow 100 \%(6-7 \mathrm{~min}) \rightarrow 5 \%(7.01-9 \mathrm{~min})$ at a flow rate of 0.3 $\mathrm{ml} / \mathrm{min}$.

\section{Secondary and Tertiary structure determination of AAR}

The secondary structure of AAR was determined by recording far-UV CD spectra on JASCO J$815 \mathrm{CD}$ polarimeter at wavelength $200-250 \mathrm{~nm}$ in a $1 \mathrm{~mm}$ quartz cuvette. The protein concentration was $3.5 \mu \mathrm{M}$ in buffer containing $50 \mathrm{mM}$ Tris, $100 \mathrm{mM} \mathrm{NaCl}, 1 \mathrm{mM}$ DTT at $\mathrm{pH}$ 7.4. AAR contains six tyrosine and six tryptophan residues, which help in exploiting the intrinsic fluorescence 
property of the protein to determine the tertiary structure of the protein via Cary Eclipse fluorimeter. The protein was excited at excitation wavelength of $280 \mathrm{~nm}$ and $295 \mathrm{~nm}$ with slid width of $10 \mathrm{~nm}$ and fluorescence emission spectra were recorded from $300 \mathrm{~nm}$ to $400 \mathrm{~nm}$ in $1 \mathrm{~cm}$ quartz cuvette. The protein concentration used was $3.5 \mu \mathrm{M}$ in buffer containing $50 \mathrm{mM}$ Tris, 100 $\mathrm{mM} \mathrm{NaCl}, 1 \mathrm{mM}$ DTT at $\mathrm{pH}$ 7.4.

\section{Thermal denaturation and renaturation profile probed by CD}

Thermal unfolding studies were carried out for the AAR $(3.5 \mu \mathrm{M})$ using CD spectroscopy. The proteins were prepared in $50 \mathrm{mM}$ Tris, $100 \mathrm{mM} \mathrm{NaCl}, 1 \mathrm{mM}$ DTT at $\mathrm{pH}$ 7.4. The sample was placed in $1 \mathrm{~mm}$ quartz cuvette and was heated from $20{ }^{\circ} \mathrm{C}$ to $90{ }^{\circ} \mathrm{C}$ with a heating rate of $1{ }^{\circ} \mathrm{C} / \mathrm{min}$ controlled by Jasco controllable Peltier PTC-423S/15. For thermal refolding studies, the $90{ }^{\circ} \mathrm{C}$ denatured AAR $(3.5 \mu \mathrm{M})$ solution was gradually cooled to $20{ }^{\circ} \mathrm{C}$ with a cooling rate of $1{ }^{\circ} \mathrm{C} / \mathrm{min}$. A continuous CD scan at varying wavelength of $210-250 \mathrm{~nm}$ was collected for each temperature and the Mean Residual Ellipticity (MRE) values were plotted against the respective temperature. The buffer was always prepared fresh at room temperature in order to minimize the heating effect on Tris. The thermal denaturation profile was analyzed when the obtained set of data was fitted in the two-state model to determine a mid-point of the transition curve using Sigma plot 11.0 software as described in the data analysis section.

\section{Thermal denaturation and renaturation profile probed by intrinsic fluorescence spectroscopy}

For the fluorescence-based thermal denaturation studies, AAR $(3.5 \mu \mathrm{M})$ in $1 \mathrm{~cm}$ quartz cuvette was placed in a thermostatic holder of Cary Eclipse fluorimeter. The holder was maintained at a constant temperature by circulating water from a constant temperature water bath. A step-wise 
heat denaturation experiment was performed. AAR solution was incubated at different temperatures varying from $20^{\circ} \mathrm{C}$ to $90^{\circ} \mathrm{C}$ for 5 min before recording the emission spectra. Each incubated sample was excited at $295 \mathrm{~nm}$ and emission spectra were recorded from 300 to $400 \mathrm{~nm}$ at all temperatures with slit width of $10 \mathrm{~nm}$. For the step-wise thermal renaturation experiment, AAR solution $(3.5 \mu \mathrm{M})$ was incubated at $90^{\circ} \mathrm{C}$ for $5 \mathrm{~min}$ and then gradually cooled. The incubated sample was excited at $295 \mathrm{~nm}$ and the intrinsic fluorescence emission spectra were recorded from 300 to $400 \mathrm{~nm}$ at different temperatures from $20{ }^{\circ} \mathrm{C}$ to $90{ }^{\circ} \mathrm{C}$.

The relative fluorescence intensity at $340 \mathrm{~nm}$ and emission maximal wavelength $\chi_{\max }$ was plotted against the temperature to obtain the thermal denaturation transition curve. The thermal denaturation profile was analyzed when the obtained set of data was fitted in the two-state model to determine a mid-point of the transition curve using Sigma plot 11.0 software as described in the data analysis section.

\section{Equilibrium Unfolding of AAR probed by CD}

Denaturant-mediated equilibrium unfolding studies were carried out using urea and $\mathrm{GdnHCl}$ as denaturant using CD spectroscopy. Spectra were recorded in the far-UV region (wavelength 200$250 \mathrm{~nm}$ ) using JASCO J-815 CD polarimeter equipped with JASCO PTC-423S/15 using $1 \mathrm{~mm}$ quartz cuvette. The samples were prepared by incubating AAR $(3.5 \mu \mathrm{M})$ with different concentrations of $\mathrm{GdnHCl}(0$ to $6 \mathrm{M})$ or urea $(0-8 \mathrm{M})$ for one hour at $25^{\circ} \mathrm{C}$ in buffer containing $50 \mathrm{mM}$ Tris, $100 \mathrm{mM} \mathrm{NaCl}$, and $1 \mathrm{mM}$ DTT at $\mathrm{pH}$ 7.4. Each spectrum was corrected against its blank. The MRE values were plotted against the denaturant concentrations to obtain an unfolding transition curve. The unfolding transition profile was analyzed when the obtained set of data was fitted in the two/ three-state model to determine a mid-point of the transition curve and steady- 
state free energy change parameters using Sigma plot 11.0 software as described in the data analysis section.

\section{Equilibrium Unfolding probed by intrinsic fluorescence spectroscopy}

The equilibrium unfolding of AAR was probed by intrinsic fluorescence as well. For this, the equilibrated samples in $1 \mathrm{~cm}$ quartz cuvette were excited at $295 \mathrm{~nm}$ and the emission spectra were recorded from 300 to $400 \mathrm{~nm}$ with a slit width of $10 \mathrm{~nm}$ each. The samples were prepared by incubating $\operatorname{AAR}(2.0 \mu \mathrm{M})$ with different concentrations of $\mathrm{GdnHCl}(0$ to $6 \mathrm{M})$ or urea $(0-8 \mathrm{M})$ for one hour at $25^{\circ} \mathrm{C}$ in buffer containing $50 \mathrm{mM}$ Tris, $100 \mathrm{mM} \mathrm{NaCl}$, and $1 \mathrm{mM}$ DTT at $\mathrm{pH}$ 7.4. Each spectrum was corrected against its blank. The relative fluorescence intensity at $340 \mathrm{~nm}$ and emission maximal wavelength $\chi_{\max }$ was plotted against the denaturant concentration to obtain the equilibrium unfolding transition curve.

\section{Data analysis of two-state equilibrium unfolding}

The urea-induced equilibrium unfolding data obtained from CD and fluorescence spectroscopy was analyzed by drawing the baseline for the native and unfolded states in the unfolding transition curve which can be further fitted to a two-state model. The proposed equilibrium is

$$
N \geq U
$$

Where $\mathrm{K}_{\mathrm{NU}}$ is the equilibrium constant for $\mathrm{N} \rightleftharpoons \mathrm{U}$

The observed signal of protein from both $\mathrm{CD}$ and fluorescence intensity of the protein $\left[\mathrm{S}_{\mathrm{obs}}(\mathrm{c})\right]$ at any concentration of denaturant is given by the sum contribution of all the two states as:

$\mathrm{S}_{\mathrm{obs}}(\mathrm{c})=\mathrm{S}_{\mathrm{N}} \mathrm{f}_{\mathrm{N}}(\mathrm{c})+\mathrm{S}_{\mathrm{U}} \mathrm{fu}_{\mathrm{U}}(\mathrm{c})$ 
$f_{N}(c), f_{U}(c)$ are the fractions of two states at a urea concentration of $c$ and $S_{N}$, and $S_{U}$ are the signal for pure $\mathrm{N}$ and $\mathrm{U}$ states respectively.

The fractions $\mathrm{f}_{\mathrm{N}}$, and $\mathrm{fu}_{\mathrm{U}}$ are related to $\mathrm{K}_{\mathrm{NU}}$ of unfolding transition from $\mathrm{N} \rightleftharpoons \mathrm{U}$ as

$\mathrm{K}_{\mathrm{NU}}=\mathrm{f}_{\mathrm{u}} / \mathrm{f}_{\mathrm{n}}$

Hence, are related to corresponding free energy change $\Delta \mathrm{G}_{\mathrm{NU}}$ as follow:

$\Delta \mathrm{G}_{\mathrm{NU}}=-\mathrm{RT} \ln \mathrm{K}_{\mathrm{NU}}$

Where $\mathrm{R}$ is gas constant and $\mathrm{T}$ is absolute temperature.

It is well-known that the free energy $\left(\Delta \mathrm{G}_{\mathrm{NU}}\right)$ of unfolded protein at different denaturant concentrations $[\mathrm{D}]$ has a linear relation with the denaturant concentration:

$$
\Delta \mathrm{G}_{\mathrm{NU}}{ }^{\mathrm{D}}=\Delta \mathrm{G}_{\mathrm{NU}} \mathrm{H}_{2} \mathrm{O}-\mathrm{m}[\mathrm{D}]
$$

Where $\Delta \mathrm{GNU}_{2} \mathrm{H}_{2} \mathrm{O}$ is the free energy of unfolding in absence of denaturant; $\mathrm{m}$ is the slope of the transition.

The observed signal of protein by CD and fluorescence intensity is given by

$\mathrm{S}_{\text {obs }}(\mathrm{c})=\mathrm{S}_{\mathrm{N}}+\mathrm{S}_{\mathrm{U}} \exp \left[-\left(\Delta \mathrm{G}_{\mathrm{NU}} \mathrm{H}_{2} \mathrm{O}-\mathrm{m}_{\mathrm{NU}} \mathrm{c}\right) / \mathrm{RT}\right] / 1+\exp \left[-\left(\Delta \mathrm{G}_{\mathrm{NU}} \mathrm{H}_{2} \mathrm{O}-\mathrm{m}_{\mathrm{NU}} \mathrm{c}\right) / \mathrm{RT}\right.$

In general $\mathrm{S}_{\mathrm{N}}$ and $\mathrm{S}_{\mathrm{U}}$ are dependent on the concentration of $\mathrm{c}$, and we assume a linear dependence on the concentration of denaturant $(\mathrm{c})$, as $\mathrm{S}_{\mathrm{N}}=\mathrm{a}_{1}+\mathrm{b}_{1} \mathrm{c}, \mathrm{S}_{\mathrm{U}}=\mathrm{c}_{1}+\mathrm{p}_{1} \mathrm{c}$; where $\mathrm{a}_{1}, \mathrm{~b}_{1}, \mathrm{c}_{1}$, and $\mathrm{p}_{1}$ are constants. $\mathrm{a}_{1}, \mathrm{~b}_{1}, \mathrm{c}_{1}, \mathrm{p}_{1}$ were calculated from intercept and slope of the baseline of the native and unfolded states. By using all the above equations, the urea-mediated equilibrium unfolding data were analyzed by a method of nonlinear least-squares analysis and thermodynamic parameters of stability were calculated. The data were fitted to this equation using the linear least-square method 
to obtain the best- fitted values of $\Delta \mathrm{GNU}_{2} \mathrm{H}_{2} \mathrm{O}$ and $\mathrm{D}_{\mathrm{m}}$. The curve fittings were performed using Sigma 11.0 software

\section{Data analysis of GdnHCl-mediated equilibrium unfolding}

The GdnHCl- induced equilibrium unfolding data obtained from $\mathrm{CD}$ and fluorescence spectroscopy was analyzed by drawing the baseline for the native, intermediate, and unfolded states in the unfolding transition curve which can be further fitted to a three-state model. The proposed equilibrium is

$$
N \geq I \geq U
$$

Where $\mathrm{K}_{\mathrm{NI}}, \mathrm{K}_{\mathrm{IU}}$, and $\mathrm{K}_{\mathrm{NU}}$ are the equilibrium constants for $\mathrm{N} \rightleftharpoons \mathrm{I}, \mathrm{I} \rightleftharpoons \mathrm{U}$, and $\mathrm{N} \rightleftharpoons \mathrm{U}$ transitions, respectively. The observed signal of protein from both $\mathrm{CD}$ and fluorescence intensity of the protein $\left[\mathrm{S}_{\mathrm{obs}}(\mathrm{c})\right]$ at any concentration of denaturant is given by the sum contribution of all the three states as:

$S_{\text {obs }}(c)=S_{N} f_{N}(c)+S_{I} f_{I}(c)+S_{U} f_{U}(c)$

$f_{\mathrm{N}}(\mathrm{c}), \mathrm{f}_{\mathrm{I}}(\mathrm{c}), \mathrm{fu}_{\mathrm{U}}(\mathrm{c})$ are the fractions of three states at a $\mathrm{GdnHCl}$ concentration of $\mathrm{c}$ and $\mathrm{S}_{\mathrm{N}}, \mathrm{S}_{\mathrm{I}}$, and $\mathrm{S}_{\mathrm{U}}$ are the signal for pure $\mathrm{N}, \mathrm{I}$, and $\mathrm{U}$ states respectively. The fractions $\mathrm{f}_{\mathrm{N}}, \mathrm{f}_{\mathrm{I}}$ and $\mathrm{f}_{\mathrm{U}}$ are related to $\mathrm{K}_{\mathrm{NI}}$ and $\mathrm{K}_{\mathrm{NU}}$ of unfolding transition from $\mathrm{N} \rightleftharpoons \mathrm{I}$ and $\mathrm{N} \rightleftharpoons \mathrm{U}$ respectively, hence are related to corresponding free energy changes $\Delta \mathrm{G}_{\mathrm{NI}}$ and $\Delta \mathrm{G}_{\mathrm{NU}}$, as follows.

$\mathrm{f}_{\mathrm{N}}=1 /\left(1+\mathrm{K}_{\mathrm{NI}}+\mathrm{K}_{\mathrm{NU}}\right)=1 /\left[1+\exp \left(-\Delta \mathrm{G}_{\mathrm{NI}} / \mathrm{RT}\right)+\exp \left(-\Delta \mathrm{G}_{\mathrm{NU}} / \mathrm{RT}\right)\right]$

$\mathrm{f}_{\mathrm{I}}=\mathrm{K}_{\mathrm{NI}} /\left(1+\mathrm{K}_{\mathrm{NI}}+\mathrm{K}_{\mathrm{NU}}\right)=\exp \left(-\Delta \mathrm{G}_{\mathrm{NI}} / \mathrm{RT}\right) /\left[1+\exp \left(-\Delta \mathrm{G}_{\mathrm{NI}} / \mathrm{RT}\right)+\exp \left(-\Delta \mathrm{G}_{\mathrm{NU}} / \mathrm{RT}\right)\right]$ 
$\mathrm{f}_{\mathrm{U}}=\mathrm{K}_{\mathrm{NU}} /\left(1+\mathrm{K}_{\mathrm{NI}}+\mathrm{K}_{\mathrm{NU}}\right)=\exp \left(\Delta \mathrm{G}_{\mathrm{NU}} / \mathrm{RT}\right) /\left[1+\exp \left(-\Delta \mathrm{G}_{\mathrm{N}} / \mathrm{RT}\right)+\exp \left(-\Delta \mathrm{G}_{\mathrm{NU}} / \mathrm{RT}\right)\right]$

Where $\mathrm{R}$ is gas constant and $\mathrm{T}$ is the absolute temperature. The free energy changes of unfolding are known to vary linearly with denaturant concentration such that

$\Delta \mathrm{G}_{\mathrm{NI}}=\Delta \mathrm{G}_{\mathrm{NI}}{ }^{\mathrm{H} 2 \mathrm{O}}-\mathrm{m} \mathrm{NI} \mathrm{C}_{\mathrm{N}}$

$\Delta \mathrm{G}_{\mathrm{NU}}=\Delta \mathrm{G}_{\mathrm{NU}}{ }^{\mathrm{H} 2 \mathrm{O}}-\mathrm{m} \mathrm{NU} \mathrm{c}$

Where $\Delta \mathrm{G}_{\mathrm{NU}}{ }^{\mathrm{H} 2 \mathrm{O}}$ and $\Delta \mathrm{G}_{\mathrm{NI}}{ }^{\mathrm{H} 2 \mathrm{O}}$ are the $\Delta \mathrm{G}_{\mathrm{NU}}$ and $\Delta \mathrm{G}_{\mathrm{NI}}$ at $0 \mathrm{M} \mathrm{GdnHCl}$ respectively and $\mathrm{m}_{\mathrm{NI}}$ and mNU represent the dependence of respective free energy changes on denaturant concentration (c) and the co-operativity of transition.

So from the equation (8) - (10), $\mathrm{S}_{\mathrm{obs}}(\mathrm{c})$ is given by:

$\operatorname{Sobs}(\mathrm{c})=\mathrm{S}_{\mathrm{N}}+\mathrm{SI}_{\mathrm{I}} \exp \left[-\left(\Delta \mathrm{GNI}^{\mathrm{H} 2 \mathrm{O}}-\mathrm{mNI}_{\mathrm{c}} \mathrm{c}\right) / \mathrm{RT}\right]+\mathrm{SU}_{\mathrm{U}} \exp \left[-\left(\Delta \mathrm{GNU}^{\mathrm{H} 2 \mathrm{O}}-\mathrm{mNU}_{\mathrm{N}} \mathrm{c}\right) / \mathrm{RT}\right] / 1+\exp \left[-\left(\Delta \mathrm{GNI}_{\mathrm{N}}\right.\right.$ $\left.\left.\mathrm{H}^{2} \mathrm{O}-\mathrm{mNI}_{\mathrm{N}} \mathrm{c}\right) / \mathrm{RT}\right]+\exp \left[-\left(\Delta \mathrm{GNU}^{\mathrm{H} 2 \mathrm{O}}-\mathrm{mNU}_{\mathrm{c}}\right) / \mathrm{RT}\right]$

In general $\mathrm{S}_{\mathrm{N}}$, SI and $\mathrm{S}_{\mathrm{U}}$ are dependent on the concentration of $\mathrm{c}$, and we assume a linear dependence on the concentration of denaturant $(c)$, as $S_{N}=a_{1}+b_{1} c, S_{I}=c_{1}+p_{1} c$ and $S_{U}=e_{1}+g_{1} c$ where $\mathrm{a}_{1}, \mathrm{~b}_{1}, \mathrm{c}_{1}, \mathrm{p}_{1}, \mathrm{e}_{1}$ and $\mathrm{g}_{1}$ are constants. $\mathrm{a}_{1}, \mathrm{~b}_{1}, \mathrm{c}_{1}, \mathrm{p}_{1}, \mathrm{e}_{1}, \mathrm{~g}_{1}$ were calculated from intercept and slope of the baseline of the native, intermediate, and unfolded states. By using all the above equations, the GdnHCl-mediated equilibrium unfolding data were analyzed by a method of nonlinear least-squares analysis and thermodynamic parameters of stability were calculated.

\section{Molecular dynamics (MD) simulations}

The crystal structure of AAR was obtained from the PDB entry 6JZU. The obtained structure was prepared before the simulation using Chimera tool [30]. The molecular dynamics on $298 \mathrm{~K}$ and 
$303 \mathrm{~K}$ were performed using AMBER18 software [31,32] and modelling and data analysis were performed by AmberTools18 suite of programs [31,32]. The parameters and atom-types of hexadecanal ligand were generated through ANTECHAMBER module and charges calculated using AM1-BCC method and the topology and parameter files were constructed using the force field leaprc.ff99SBxildn for the AAR protein. The systems were solvated with water molecules using the $10 \dot{A}$ pad of TIP3P water model. Neutralizing counter $\mathrm{Na}^{+}$ions were added first, thereafter based on the required concentrations for the study the $\mathrm{Cl}^{-}$and $\mathrm{K}^{+}$ions were added to obtain respective systems of $0,125,250,500$ and $1000 \mathrm{mM}$ of $\mathrm{KCl}$ environment. The energy minimization procedure included initial 500 cycles of steep descent (SD) algorithm followed by remaining 19500 cycles of conjugate gradient algorithm (CG) totaling 20000 steps. The systems were heated from $0 \mathrm{~K}$ to $298 \mathrm{~K}$ and $303 \mathrm{~K}$ over $50 \mathrm{ps}$ with a collision frequency of $2.0 \mathrm{ps}^{-1}$ and weak harmonic restraints of $2 \mathrm{Kcal} \mathrm{mol}^{-1} \AA^{-2}$ on all atoms using Langevin thermostat for temperature regulation. The next step was accompanied by density equilibration (50 ps) and constant pressure equilibration (5 ns). The final production molecular dynamics simulations were performed for $500 \mathrm{~ns}$ time interval at $298 \mathrm{~K}$ and $303 \mathrm{~K}$ temperatures on respective systems of 0 , $125,250,500$ and $1000 \mathrm{mM}$ of $\mathrm{KCl}$ and the trajectory was saved at every 2 ps. All molecular simulations were performed using PMEMD module in AMBER18. The time step of $2 \mathrm{fs}$ was used for all MD stages and all atoms involving hydrogen atoms were constrained using the SHAKE algorithm. The CPPTRAJ module [33] of AmberTools18 was used to perform the RMSD, RMSF and cluster analysis of trajectories. Molecular Mechanics Generalized Born Surface Area (MMGBSA) based end-point energy calculation was conducted to understand free energy differences between each system. The binding energies of AAR bound with hexadecanal ligand were calculated using 100 snapshots taken from last $200 \mathrm{~ns}$ MD trajectory. Cluster representative of the 
largest cluster was taken from each system at different temperatures from their respective MD trajectories using CPPTRAJ module of AmberTools18 for generating structures for comparison.

\section{List of abbreviations}

The abbreviations used are: AAR, acyl- acyl carrier protein reductase; ADO, aldehydedeformylating oxygenase; $\mathrm{ACP}$, acyl carrier protein; $\mathrm{CD}$, circular dichroism; coA, coenzyme A; DLS, dynamic light scattering; GdnHCl, guanidine hydrochloride; GFC, gel filtration chromatography; IPTG, isopropyl $\beta$ - d-1-thiogalactopyranoside; MS, mass spectrometry; NADPH, nicotinamide adenine dinucleotide phosphate; UHPLC, ultra-high performance liquid chromatography; UV, ultra violet.

\section{Declarations}

\section{Ethics approval and consent to participate}

Not Applicable

\section{Consent for publication}

Not Applicable

\section{Availability of data and materials}

All data generated or analysed during this study are included in this published article and its supplementary information files.

\section{Competing interests}

The authors declare that they have no competing interests

\section{Funding}


This study was funded by Department of Biotechnology, Government of India via Bioenergy Centre grant no. BT/PR/Centre/03/2011-Phase II.

\section{Author contributions}

A.S, S.S.Y designed the experiments. A.S. conducted the experiments. A.S. and T.S. optimized protein expression and purification, A.S. and G.H.R carried out mass spectrometry-related experiments. M.G. carried out MD simulation based experiments. A.S, S.S.Y analyzed the data. A.S, S.S.Y wrote and edited the manuscript. S.S.Y. secured funding.

\section{Acknowledgments}

The authors gratefully acknowledge Prof. Tapan K Chaudhuri from Kusuma School of Biological Sciences, Indian Institute of Technology Delhi for allowing the use of instruments in his laboratory. Authors also thank Dr. Arockiasamy Arulandu from ICGEB New Delhi for his kind suggestions during preparation of protein and DLS experiments.

\section{References}

1. Zhou YJ, Kerkhoven EJ, Nielsen J. Barriers and opportunities in bio-based production of hydrocarbons. Nature Energy. 2018;3(11):925-35.

2. Shakeel T, Sharma A, Yazdani SS. Building cell factories for the production of advanced fuels. Biochemical Society Transactions. 2019;47(6):1701-14.

3. Zhang Y, Nielsen J, Liu Z. Metabolic engineering of Saccharomyces cerevisiae for production of fatty acid-derived hydrocarbons. Biotechnology and bioengineering. 2018;115(9):2139-47. 
4. Liao JC, Mi L, Pontrelli S, Luo S. Fuelling the future: microbial engineering for the production of sustainable biofuels. Nature Reviews Microbiology. 2016;14(5):288.

5. Hu Y, Zhu Z, Nielsen J, Siewers V. Engineering Saccharomyces cerevisiae cells for production of fatty acid-derived biofuels and chemicals. Open biology.2019;9(5):190049.

6. Zhou YJ, Buijs NA, Zhu Z, Gómez DO, Boonsombuti A, Siewers V, Nielsen J. Harnessing yeast peroxisomes for biosynthesis of fatty-acid-derived biofuels and chemicals with relieved sidepathway competition. Journal of the American Chemical Society. 2016;138(47): 15368-77.

7. Hassan SN, Sani YM, Aziz AA, Sulaiman NMN, Daud WMAW. Biogasoline: An out-of-thebox solution to the food-for-fuel and land-use competitions. Energy Conversion and Management. 2015;89:349-67.

8. Fatma Z, Hartman H, Poolman MG, Fell DA, Srivastava S, Shakeel T, Yazdani, SS. Modelassisted metabolic engineering of Escherichia coli for long chain alkane and alcohol production. Metabolic engineering. 2018;46:1-12.

9. Fatma Z, Jawed K, Mattam AJ, Yazdani SS. Identification of long chain specific aldehyde reductase and its use in enhanced fatty alcohol production in E. coli. Metabolic engineering. 2016;37:35-45.

10. Schirmer A, Rude MA, Li X, Popova E, Del Cardayre SB. Microbial biosynthesis of alkanes. Science. 2010;329(5991):559-62.

11. Lin F, Das D, Lin XN, Marsh ENG. Aldehyde-forming fatty acyl-CoA reductase from cyanobacteria: expression, purification and characterization of the recombinant enzyme. The FEBS journal. 2013;280(19):4773-81. 
12. Warui DM, Li N, Nørgaard H, Krebs C, Bollinger Jr JM, Booker SJ. Detection of formate, rather than carbon monoxide, as the stoichiometric coproduct in conversion of fatty aldehydes to alkanes by a cyanobacterial aldehyde decarbonylase. Journal of the American Chemical Society. 2011;133(10):3316-19.

13. Eser BE, Das D, Han J, Jones PR, Marsh, ENG. Oxygen-independent alkane formation by nonheme iron-dependent cyanobacterial aldehyde decarbonylase: investigation of kinetics and requirement for an external electron donor. Biochemistry;2011;50(49):10743-50.

14. Kudo H, Nawa R, Hayashi Y, Arai M. Comparison of aldehyde-producing activities of cyanobacterial acyl-(acyl carrier protein) reductases. Biotechnology for biofuels. 2016;9(1):234.

15. Gao Y, Zhang H, Fan M, Jia C, Shi L, Pan X,....Li M. Structural insights into catalytic mechanism and product delivery of cyanobacterial acyl-acyl carrier protein reductase. Nature communications.2020;11(1):1-11.

16. Shakeel T, Gupta M, Fatma Z, Kumar R, Kumar R, Singh R, ... Yazdani, SS. A consensusguided approach yields a heat-stable alkane-producing enzyme and identifies residues promoting thermostability. Journal of Biological Chemistry.2018;293(24):9148-61.

17. Shah MA, Mishra S, Chaudhuri, TK. Marginal stability drives irreversible unfolding of large multi-domain family 3 glycosylhydrolases from thermo-tolerant yeast. International journal of biological macromolecules. 2018;108:1322-30.

18. Kudo H, Hayashi Y, Arai M. Improving hydrocarbon production by engineering cyanobacterial acyl-(acyl carrier protein) reductase. Biotechnology for Biofuels.2019;12(1):291. 
19. Shioda N, Yabuki Y, Kobayashi Y, Onozato M, Owada Y, Fukunaga, K. FABP3 protein promotes $\alpha$-synuclein oligomerization associated with 1-methyl-1, 2, 3, 6-tetrahydropiridineinduced neurotoxicity. Journal of Biological Chemistry. 2014;289(27):18957-65.

20. Ghosh K, Dill, K. Cellular proteomes have broad distributions of protein stability. Biophysical journal. 2010;99(12):3996-4002.

21. Ghaemmaghami S, Oas, TG. Quantitative protein stability measurement in vivo. Nature structural biology. 2001;8(10):879-82.

22. Ignatova Z, Gierasch LM. Monitoring protein stability and aggregation in vivo by real-time fluorescent labeling. Proceedings of the National Academy of Sciences. 2004;101(2):523-28.

23. Brissos V, Goncalves N, Melo EP, Martins LO. Improving kinetic or thermodynamic stability of an azoreductase by directed evolution. PLoS One. 2014;9(1).

24. Mayr LM, Schmid, FX. Stabilization of a protein by guanidinium chloride. Biochemistry. 1993;32(31): 7994-98.

25. Ahmad A, Akhtar MS, Bhakuni V. Monovalent cation-induced conformational change in glucose oxidase leading to stabilization of the enzyme. Biochemistry. 2001;40(7):1945-55.

26. Rashid F, Sharma S, Bano B. Comparison of guanidine hydrochloride ( $\mathrm{GdnHCl}$ ) and urea denaturation on inactivation and unfolding of human placental cystatin (HPC). The protein journal. 2005;24(5):283-92.

27. Monera OD, Zhou NE, Kay CM, Hodges RS. Comparison of antiparallel and parallel twostranded alpha-helical coiled-coils. Design, synthesis, and characterization. Journal of Biological Chemistry.1993;268(26):19218-27. 
28. Ortega G, Laín A, Tadeo X, López-Méndez B, Castano D, Millet O. Halophilic enzyme activation induced by salts. Scientific reports. 2011;1:6.

29. Malhotra P, Udgaonkar JB. How cooperative are protein folding and unfolding transitions? Protein Science. 2016;25(11):1924-41.

30. Pettersen EF, Goddard TD, Huang CC, Couch GS, Greenblatt DM, Meng EC, Ferrin TE. UCSF Chimera - a visualization system for exploratory research and analysis. Journal of computational chemistry.2004;25(13):1605-12.

31. Case DA, Ben-Shalom IY, Brozell SR, Cerutti DS,...., Kollman PA. AMBER 2018, University of California, San Francisco. 2018

32. Case DA, Cheatham TE 3rd, Darden T, Gohlke H, Luo R, Merz KM Jr, Onufriev A, Simmerling C, Wang B, Woods RJ. The Amber biomolecular simulation programs. J. Comput. Chem. 2005;26:1668-88.

33. Roe DR, Cheatham TE, 3rd. PTRAJ and CPPTRAJ: software for processing and analysis of molecular dynamics trajectory data. J. Chem. Theory Comput. 2013;9:3084-95.

\section{Figures and figure legends}

Figure 1. (A) Domain organization of AAR. I, II, III represents intrinsic flexible regions in the respective domains. (B) Expression and purification of AAR. 12\% SDS PAGE showing expression of AAR in E. coli cells. Lane M, medium-range protein molecular weight marker; Lane UI, uninduced M15 (pQE30 AAR) E. coli cells; Lane I, Induced M15 (pQE30AAR) cells; Lane 
Ni-NTA, Ni-NTA chromatography purified AAR; Lane GFC, GFC purified and concentrated AAR.

Figure 2. Enzymatic activity assay of AAR. Panels represent Total Ion Current (TIC) chromatogram probed by Gas Chromatography-Mass spectrometry (GC-MS) of the analyzed reaction product (hexadecanal) at different time intervals $0 \mathrm{~h}(\mathrm{~A})$ and $4 \mathrm{~h}(\mathrm{~B})$. (C) Mass spectrum of the peak corresponding to hexadecanal, Inset represents the mass spectrum of the hexadecanal from the database library

Figure 3. Dynamic-light-scattering distribution curves of AAR. Panel A, B, C, and D represent intensity size distribution curves for AAR GFC pooled fractions a, b, c, and d respectively. The concentration of each pooled fraction was $1 \mathrm{mg} / \mathrm{mL}$.

Figure 4. Intact mass determination of AAR using LC-ESI Mass spectroscopy. (A) Deconvoluted mass spectrum of AAR; inset shows full ESI-MS Scan profile of AAR. (B) Intact mass determination of de-lipidated AAR using LC-ESI Mass spectroscopy- deconvoluted Mass spectrum of MAYI-ODS treated AAR; inset shows full ESI-MS scan of MAYI-ODS treated AAR.

Figure 5. Secondary and tertiary structure determination of AAR. A. Graph shows Far-UV CD spectra of AAR $(3.5 \mu \mathrm{M})$ monitored from 250-200 nm wavelength to determine secondary structure. Tertiary structure determination of AAR probed by intrinsic fluorescence spectroscopy was performed by (B) Intrinsic (Trp + Tyr) emission fluorescence spectra of AAR (3.5 $\mu \mathrm{M})$ with excitation at $280 \mathrm{~nm}$, and (C) intrinsic (Trp) emission fluorescence spectra of AAR with excitation at $295 \mathrm{~nm}$.

Figure 6. Thermal unfolding and refolding profile of AAR. Upper panel represents thermal unfolding and refolding probed by CD spectroscopy. (A) Graph shows CD spectra of AAR (3.5 
$\mu \mathrm{M}$ ) when subjected to different temperatures varying from $20^{\circ} \mathrm{C}$ to $90^{\circ} \mathrm{C}$. (B) Graph represents thermal unfolding $\left(20-90^{\circ} \mathrm{C}\right)$ and refolding transition $\left(90-20^{\circ} \mathrm{C}\right)$ curve of AAR monitored by CD spectroscopy at $222 \mathrm{~nm}$. The intercept and slope of baselines, of the unfolding transition curve, were used for fitting data in two state model represented by dotted line. The inset of graph represents the $\mathrm{MRE}_{222}$ values of AAR protein corresponding to different temperatures during thermal unfolding and refolding transition. Lower panel represents thermal unfolding and refolding probed by intrinsic fluorescence spectroscopy. (C) Graph represents unfolding of AAR subjected to different temperatures from 20 to $90{ }^{\circ} \mathrm{C}$. Fluorescence emission spectra of AAR monitored from 300 to $400 \mathrm{~nm}$ when excited at $295 \mathrm{~nm}$ at varying temperatures. Fluorescence intensity decreases with increase in temperature. (D) Graph represents the relative fluorescence intensity at $340 \mathrm{~nm}$ of AAR subjected to different temperatures $\left(20-90^{\circ} \mathrm{C}\right)$. The secondary axis plot shows the change in the emission maximum $\left(\lambda_{\max }\right)$ with increasing temperature. The intercept and slope of baselines, of the unfolding transition curve, were used for fitting of data in two state unfolding model.

Figure 7. Urea-mediated equilibrium unfolding of AAR. Upper panel represents urea-mediated equilibrium unfolding probed by $\mathrm{CD}$ spectroscopy. (A) Graph shows the urea-induced unfolding profile of AAR $(3.5 \mu \mathrm{M})$ monitored by far-UV CD at $222 \mathrm{~nm}$ at different varying concentrations of urea. The intercept and slope of baselines, of the unfolding transition curve, were used for fitting of data in Equation 6 (data analysis section). (B) Graph shows far-UV CD spectra of AAR at different urea concentrations. Lower panel represents urea-mediated unfolding probed by intrinsic fluorescence spectroscopy. (C) Graph shows fluorescence emission spectra of AAR monitored from 310 to $400 \mathrm{~nm}$ when excited at $295 \mathrm{~nm}$ at different concentration of urea. (D) Graph represents the relative fluorescence intensity of AAR at $340 \mathrm{~nm}$ subjected to varying urea 
concentration. The secondary axis plot shows the change in the emission maximum $\left(\lambda_{\max }\right)$ at different concentrations of urea. The intercept and slope of baselines, of the unfolding transition curve, were used for fitting of data in Equation 6 (data analysis section).

Figure 8. GdnHCl-mediated equilibrium unfolding of AAR. Upper panel represents GdnHClmediated equilibrium unfolding of AAR probed by CD spectroscopy. (A) Graph shows far-UV CD spectra of AAR at different GdnHCl concentrations. (B) Graph shows the GdnHCl-induced unfolding profile of AAR $(3.5 \mu \mathrm{M})$ monitored by far-UV CD at $222 \mathrm{~nm}$ at different varying concentration of denaturant. The intercept and slope of baselines, of the unfolding transition curve, were used for fitting of data in Equation 11 (data analysis section). Middle panel represents GdnHCl-mediated equilibrium unfolding of AAR probed by intrinsic fluorescence spectroscopy. (C) Graph shows fluorescence emission spectra of AAR monitored from 310 to $400 \mathrm{~nm}$ when excited at $295 \mathrm{~nm}$ at different concentration of $\mathrm{GdnHCl}$. The inset graph represents the fluorescence intensity of AAR at $340 \mathrm{~nm}$ when subjected to varying AAR concentration. (D) Graph shows the change in the emission maximum $\left(\lambda_{\max }\right)$ at different concentration of urea. The intercept and slope of baselines, of the unfolding transition curve, were used for fitting of data in Equation 11 (data analysis section). (E) Panel represents theoretical curve showing different population during GdnHCl-induced unfolding pathway of AAR. Graph shows the GdnHCl concentration dependence of populations of native (N), intermediate (I) and unfolded state (U) of AAR calculated from the thermodynamic parameters listed in Table 3.

Figure 9. Molecular dynamics simulations of AAR. (A) The free energy values of AAR subjected to different concentrations of $\mathrm{KCl}$ ranging from 0 to $1000 \mathrm{mM}$. Energies were derived from Molecular Mechanics Generalized Born Surface Area (MMGBSA) calculations. (B, C) The cluster representations of AAR at $0 \mathrm{M}$ and $375 \mathrm{mM} \mathrm{KCl}$ over a 200-ns trajectory at 2-ns intervals. The enzymes are colored by RMSF, 
where red represents the highest fluctuations, and blue represents the lowest fluctuations. Highlighted R1, R2, R3, R4, R5, and R6 correspond to (A223-V230), (L69-R72), (L114-E123), (A188-N190), (A14-D16), and (D28-S35) regions of AAR respectively. (D, E). The surface view of the cluster representative of AAR subjected to $0 \mathrm{M}$ and $375 \mathrm{mM} \mathrm{KCl}$ solvent environment. 


\section{Figures}

A.

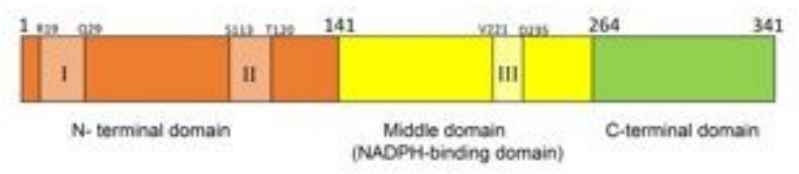

B.

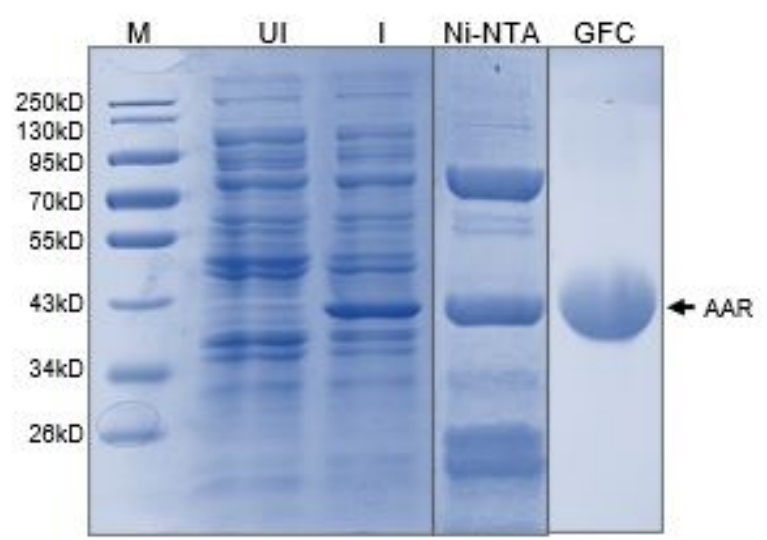

\section{Figure 1}

(A) Domain organization of AAR. I, II, III represents intrinsic flexible regions in the respective domains. (B) Expression and purification of AAR. 12\% SDS PAGE showing expression of AAR in E. coli cells. Lane M, medium-range protein molecular weight marker; Lane UI, uninduced M15 (pQE30 AAR) E. coli cells; Lane I, Induced M15 (pQE30AAR) cells; Lane Ni-NTA, Ni-NTA chromatography purified AAR; Lane GFC, GFC purified and concentrated AAR. 
A.

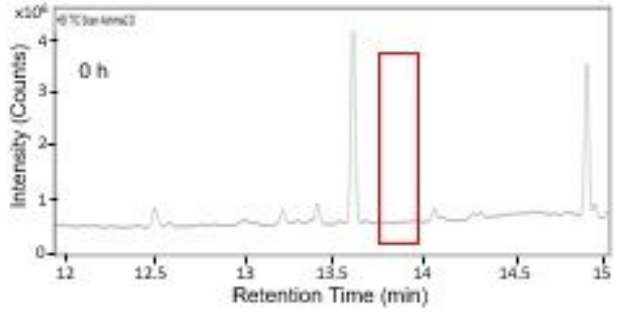

B.

C.
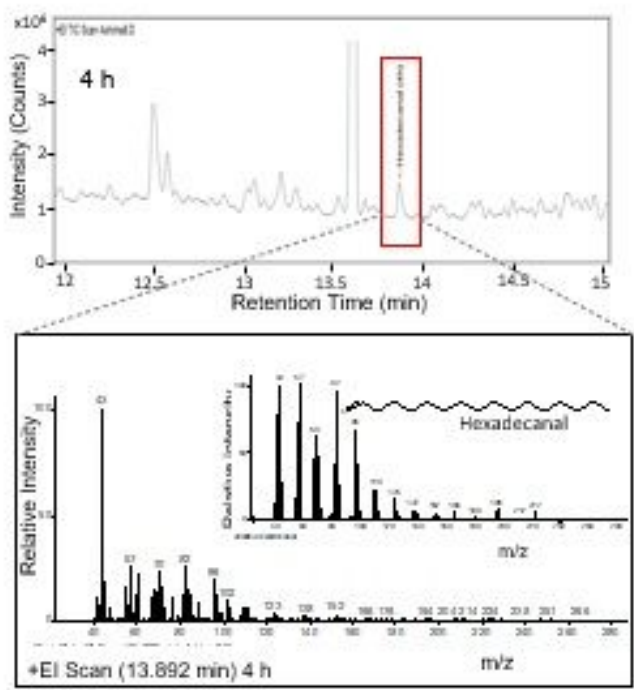

\section{Figure 2}

Enzymatic activity assay of AAR. Panels represent Total Ion Current (TIC) chromatogram probed by Gas Chromatography-Mass spectrometry (GC-MS) of the analyzed reaction product (hexadecanal) at different time intervals $0 \mathrm{~h}(\mathrm{~A})$ and $4 \mathrm{~h}(\mathrm{~B})$. (C) Mass spectrum of the peak corresponding to hexadecanal, Inset represents the mass spectrum of the hexadecanal from the database library 
A.

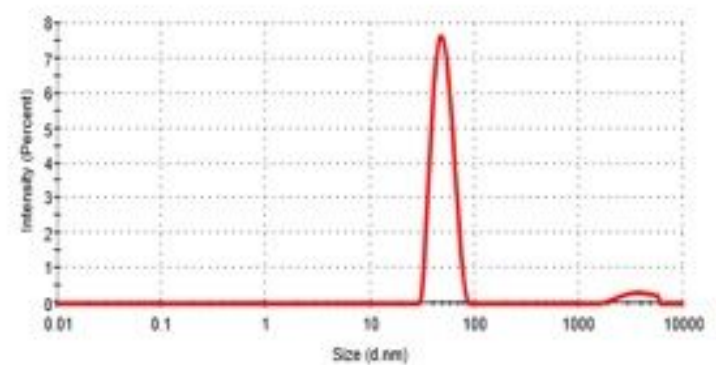

C.

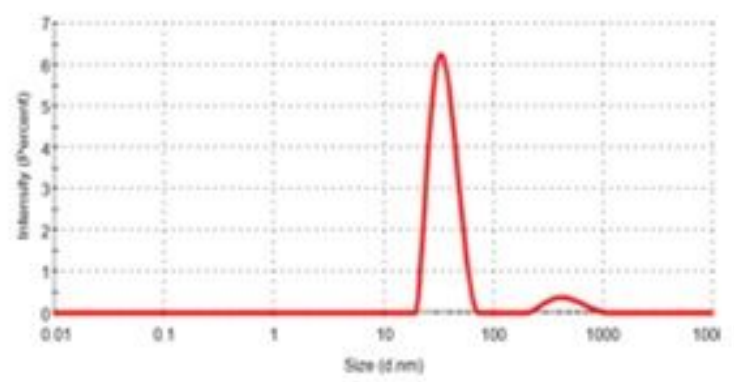

B.

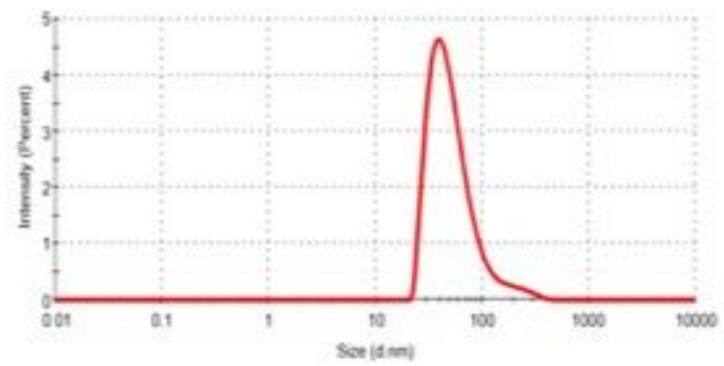

D.

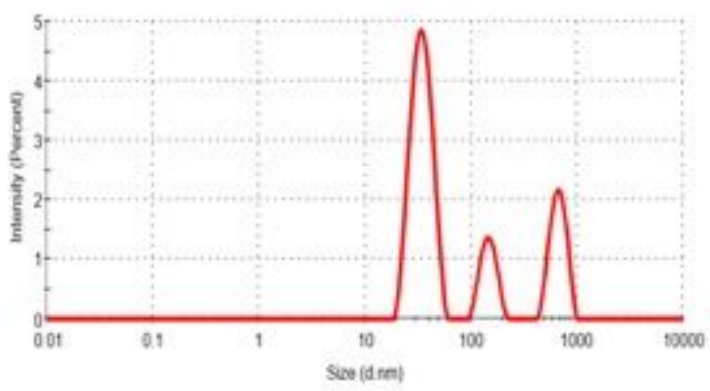

\section{Figure 3}

Dynamic-light-scattering distribution curves of AAR. Panel A, B, C, and D represent intensity size distribution curves for AAR GFC pooled fractions $a, b, c$, and d respectively. The concentration of each pooled fraction was $1 \mathrm{mg} / \mathrm{mL}$. 
A.

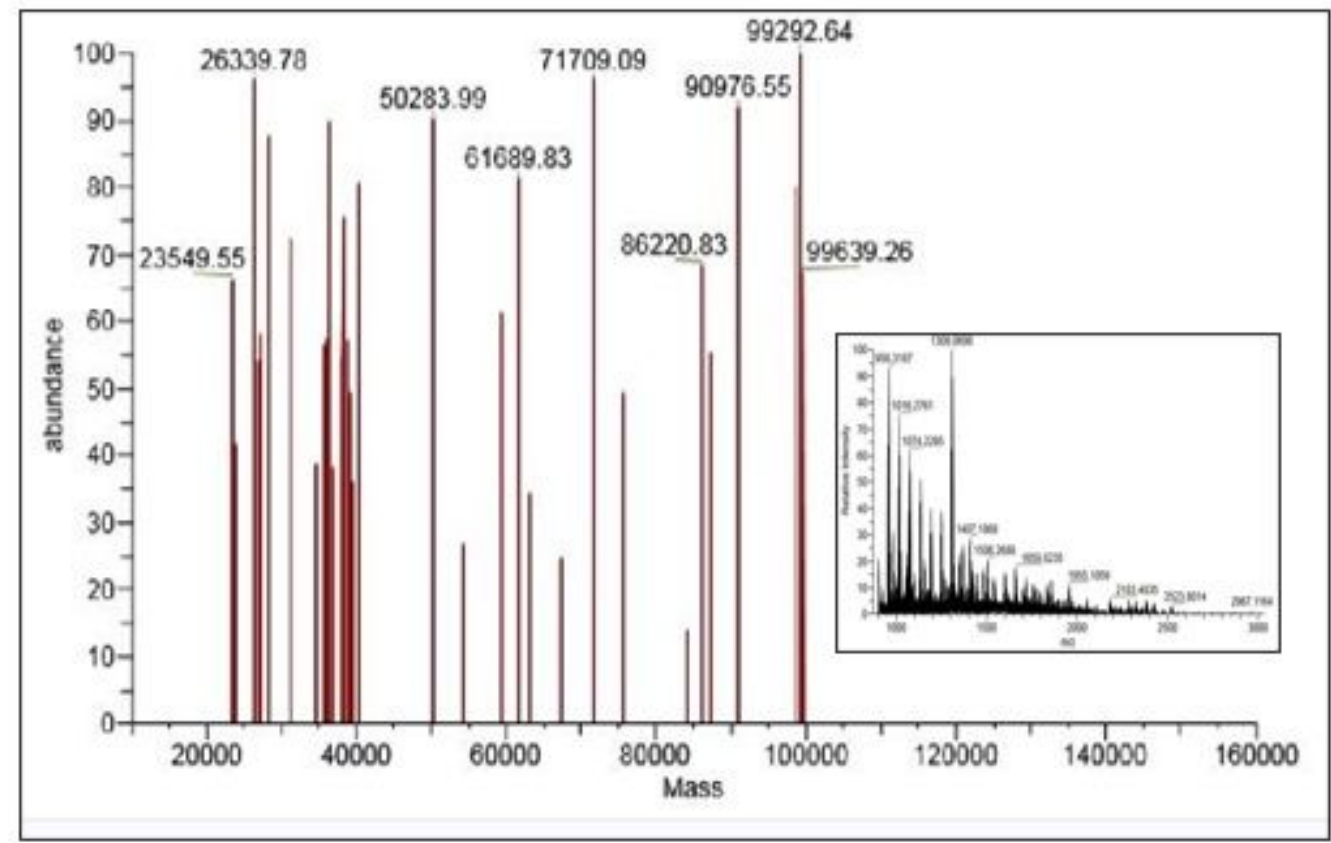

B.

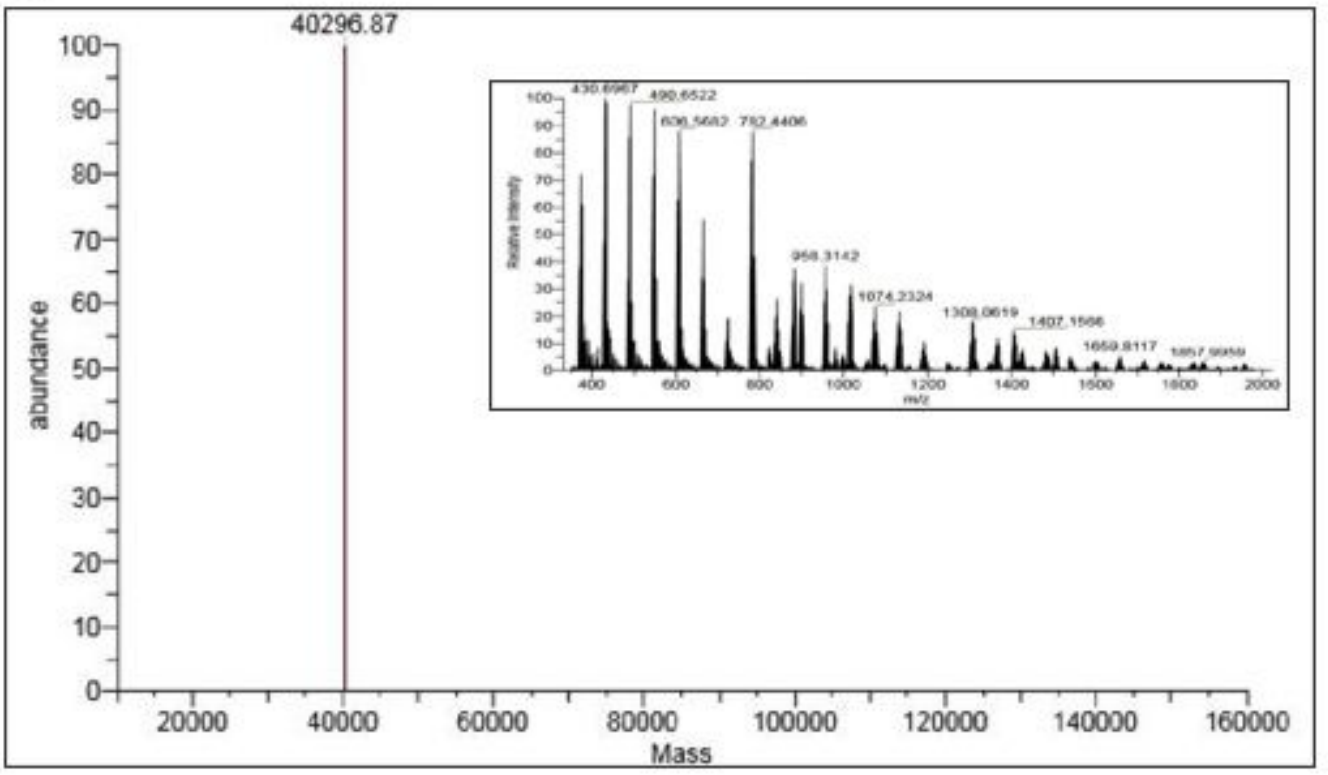

Figure 4

Intact mass determination of AAR using LC-ESI Mass spectroscopy. (A) Deconvoluted mass spectrum of AAR; inset shows full ESI-MS Scan profile of AAR. (B) Intact mass determination of de-lipidated AAR using LC-ESI Mass spectroscopy- deconvoluted Mass spectrum of MAYI-ODS treated AAR; inset shows full ESI-MS scan of MAYI-ODS treated AAR. 


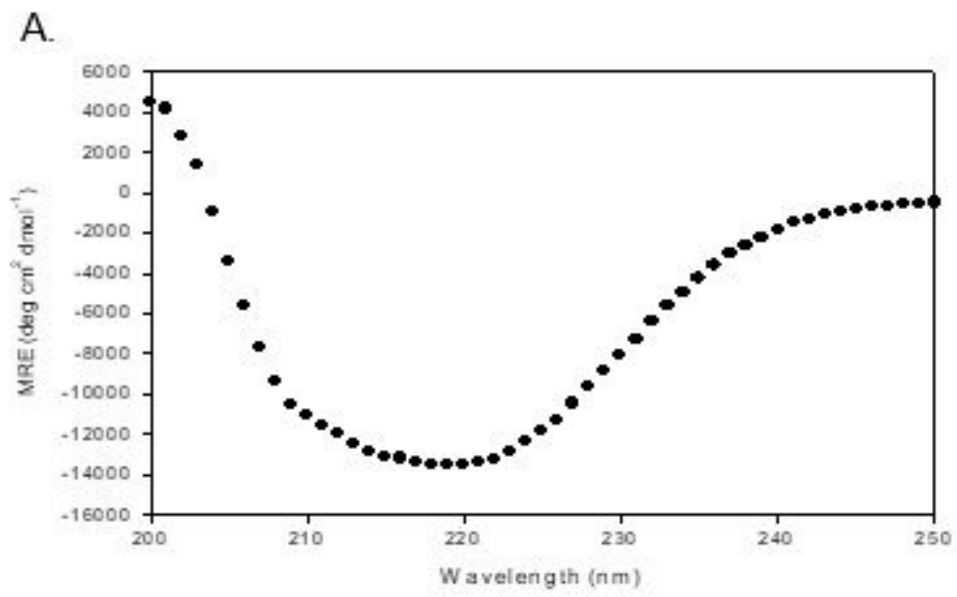

B.

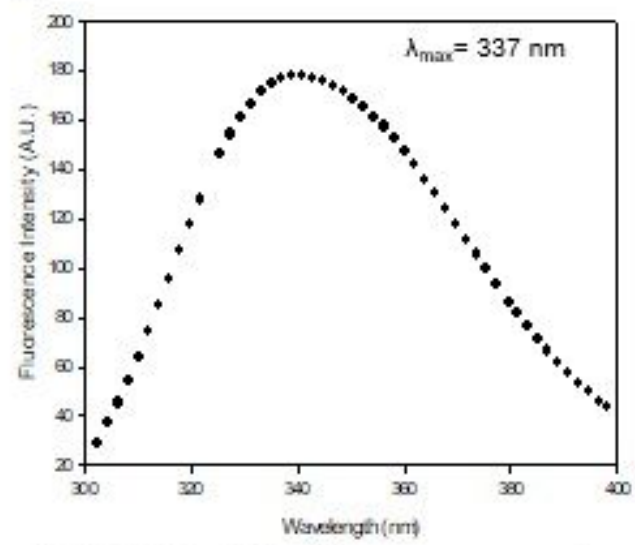

Intrinsic (Tyr + Trp) fluorescence spectra
C.

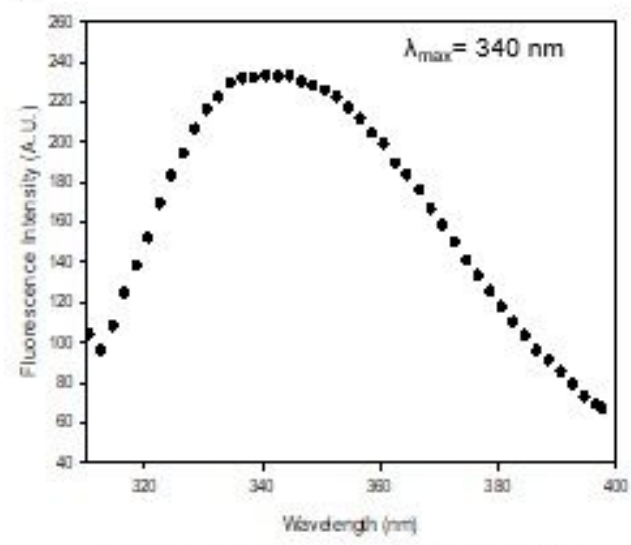

Intrinsic (Trp) fluorescence spectra

\section{Figure 5}

Secondary and tertiary structure determination of AAR. A. Graph shows Far-UV CD spectra of AAR (3.5 $\mu \mathrm{M})$ monitored from 250-200 nm wavelength to determine secondary structure. Tertiary structure determination of AAR probed by intrinsic fluorescence spectroscopy was performed by (B) Intrinsic (Trp + Tyr) emission fluorescence spectra of AAR $(3.5 \mu \mathrm{M})$ with excitation at $280 \mathrm{~nm}$, and (C) intrinsic (Trp) emission fluorescence spectra of AAR with excitation at $295 \mathrm{~nm}$. 
A.

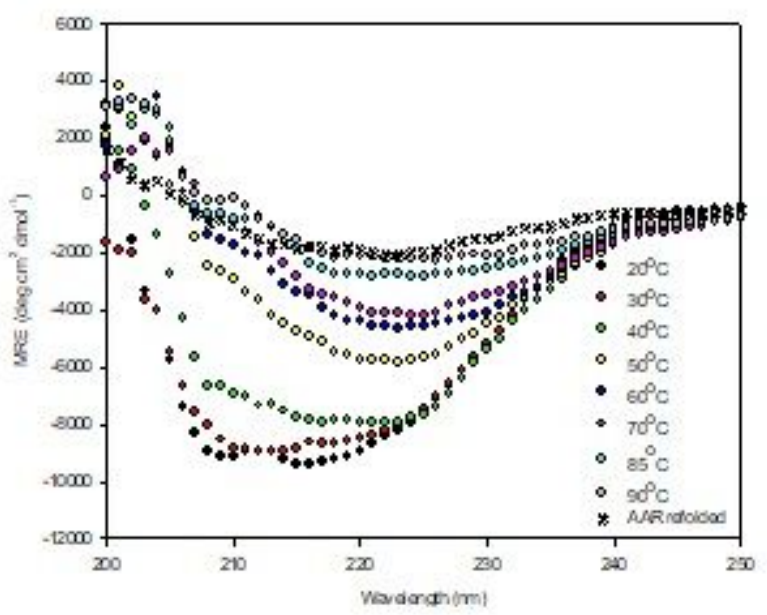

C.

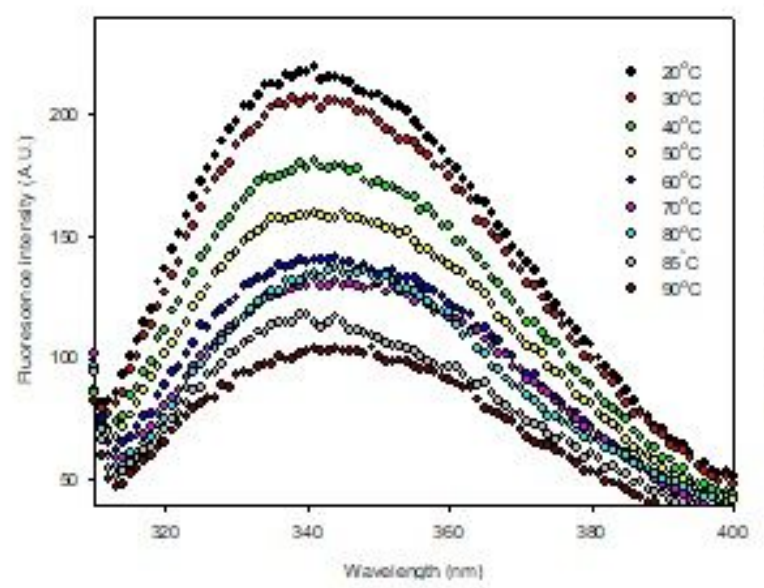

B.

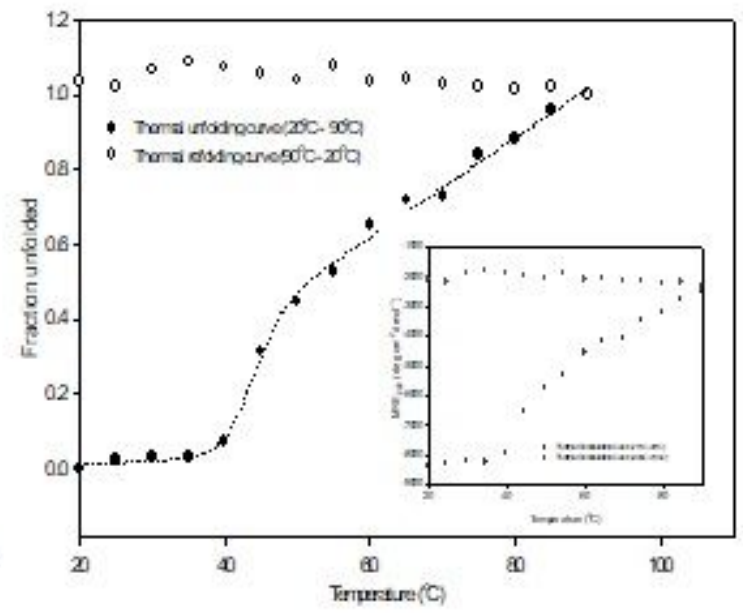

D.

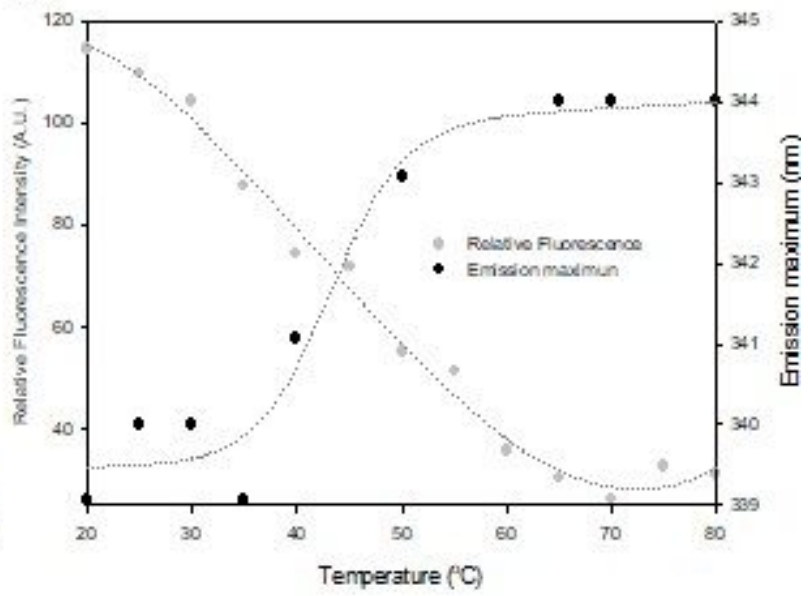

Figure 6

Thermal unfolding and refolding profile of AAR. Upper panel represents thermal unfolding and refolding probed by CD spectroscopy. (A) Graph shows CD spectra of AAR $(3.5 \mu \mathrm{M})$ when subjected to different temperatures varying from $20 \mathrm{oC}$ to $90 \mathrm{oC}$. (B) Graph represents thermal unfolding $(20-90 \mathrm{oC})$ and refolding transition $(90-20 \mathrm{oC}$ ) curve of AAR monitored by CD spectroscopy at $222 \mathrm{~nm}$. The intercept and slope of baselines, of the unfolding transition curve, were used for fitting data in two state model represented by dotted line. The inset of graph represents the MRE222 values of AAR protein corresponding to different temperatures during thermal unfolding and refolding transition. Lower panel represents thermal unfolding and refolding probed by intrinsic fluorescence spectroscopy. (C) Graph represents unfolding of AAR subjected to different temperatures from 20 to $90 \mathrm{oC}$. Fluorescence emission spectra of AAR monitored from 300 to $400 \mathrm{~nm}$ when excited at $295 \mathrm{~nm}$ at varying temperatures. Fluorescence intensity decreases with increase in temperature. (D) Graph represents the relative fluorescence intensity at $340 \mathrm{~nm}$ of AAR subjected to different temperatures (20-90 oC). The secondary axis plot shows the change in the emission maximum ( $\lambda \mathrm{max}$ ) with increasing temperature. The intercept 
and slope of baselines, of the unfolding transition curve, were used for fitting of data in two state unfolding model.

A.

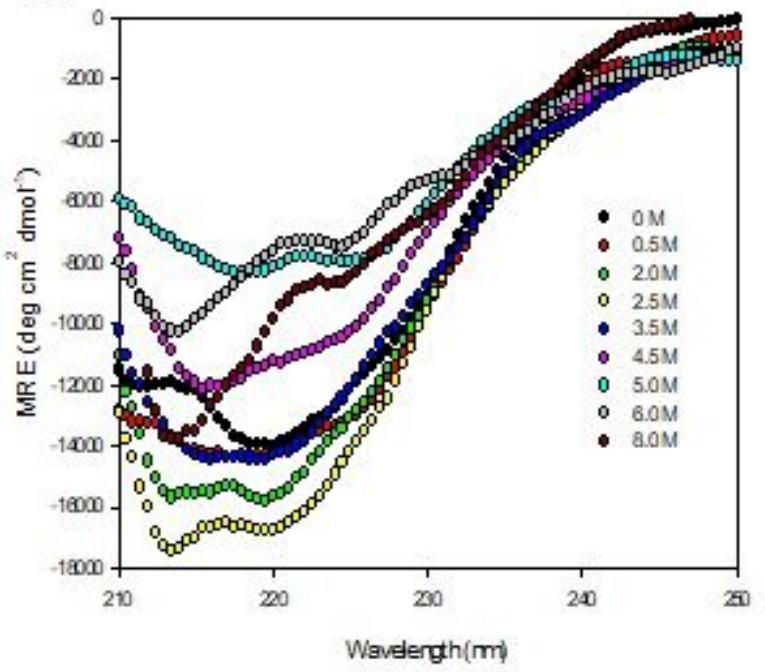

C.

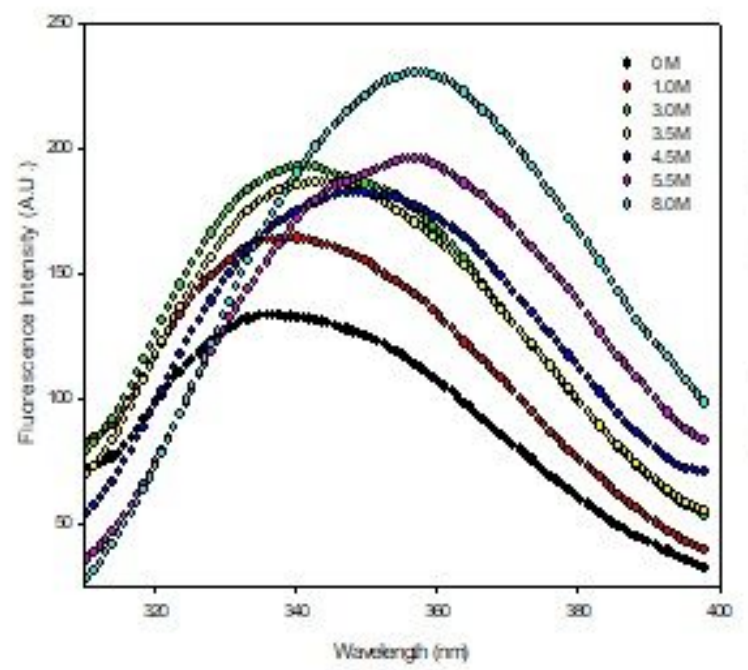

B.

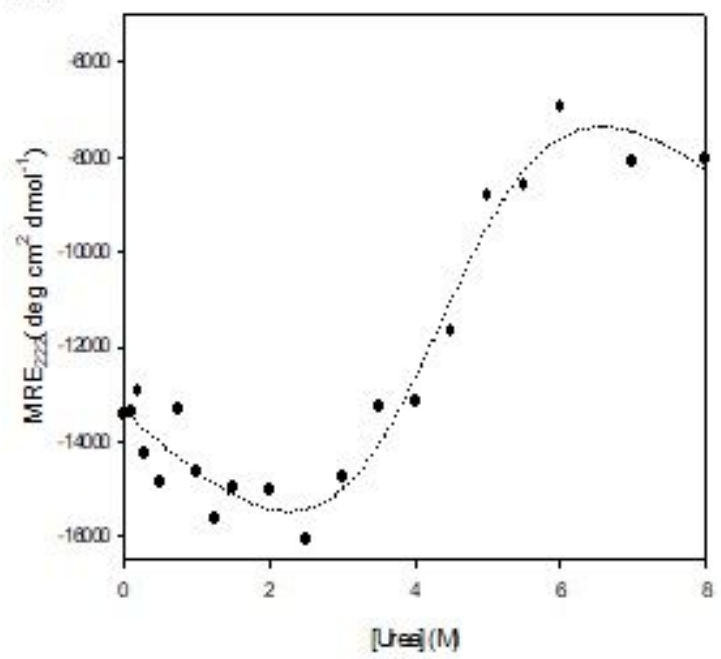

D.

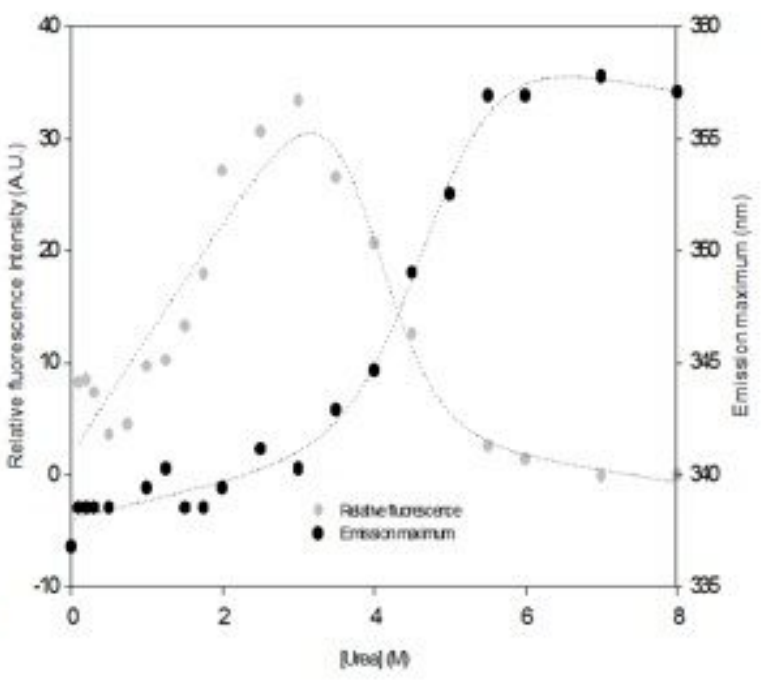

Figure 7

Urea-mediated equilibrium unfolding of AAR. Upper panel represents urea-mediated equilibrium unfolding probed by CD spectroscopy. (A) Graph shows the urea-induced unfolding profile of AAR $(3.5 \mu \mathrm{M})$ monitored by far-UV CD at $222 \mathrm{~nm}$ at different varying concentrations of urea. The intercept and slope of baselines, of the unfolding transition curve, were used for fitting of data in Equation 6 (data analysis section). (B) Graph shows far-UV CD spectra of AAR at different urea concentrations. Lower panel represents urea-mediated unfolding probed by intrinsic fluorescence spectroscopy. (C) Graph shows fluorescence emission spectra of AAR monitored from 310 to $400 \mathrm{~nm}$ when excited at $295 \mathrm{~nm}$ at different concentration of urea. (D) Graph represents the relative fluorescence intensity of AAR at $340 \mathrm{~nm}$ subjected to varying urea concentration. The secondary axis plot shows the change in the emission 
maximum ( $\lambda \max$ ) at different concentrations of urea. The intercept and slope of baselines, of the unfolding transition curve, were used for fitting of data in Equation 6 (data analysis section).

A.

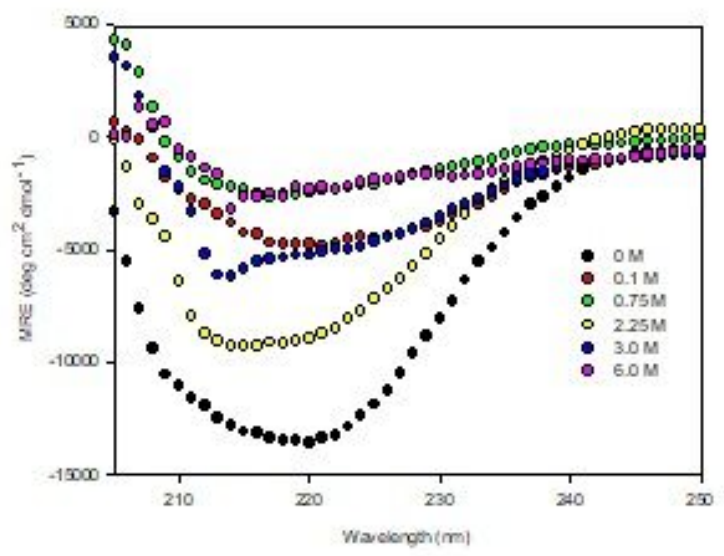

C.

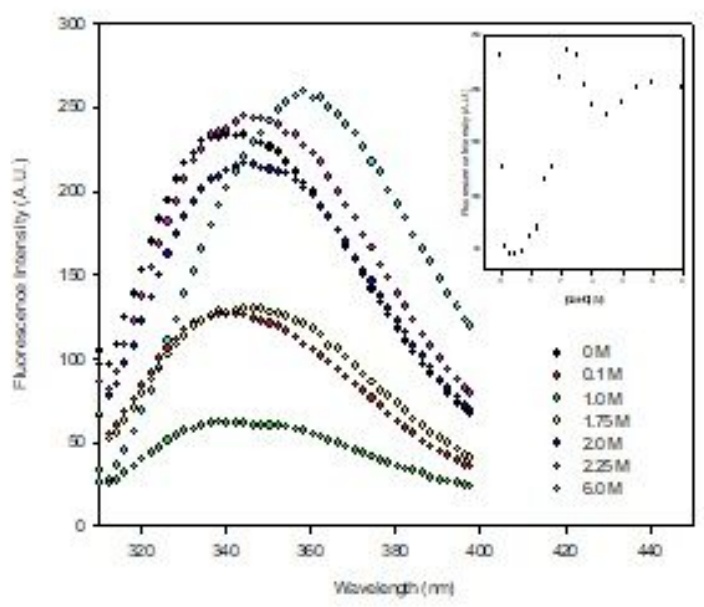

E.

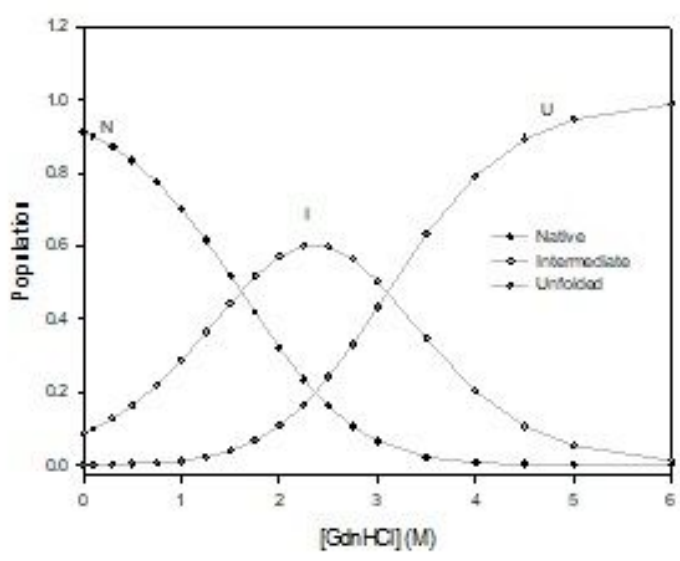

B.

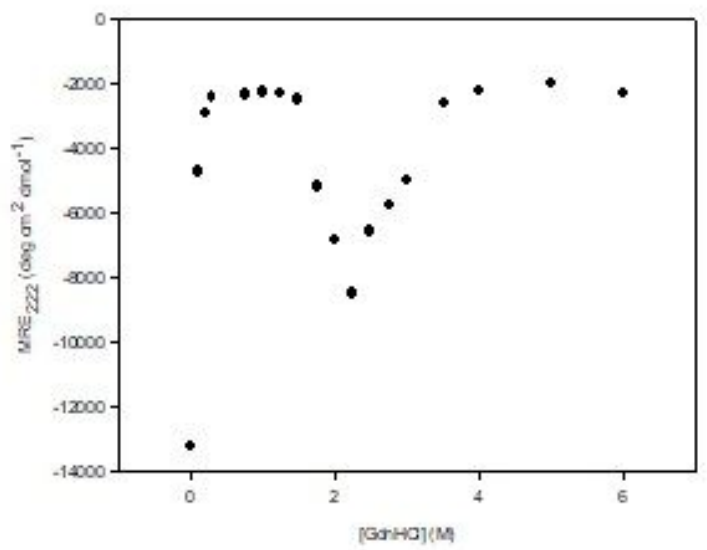

D.

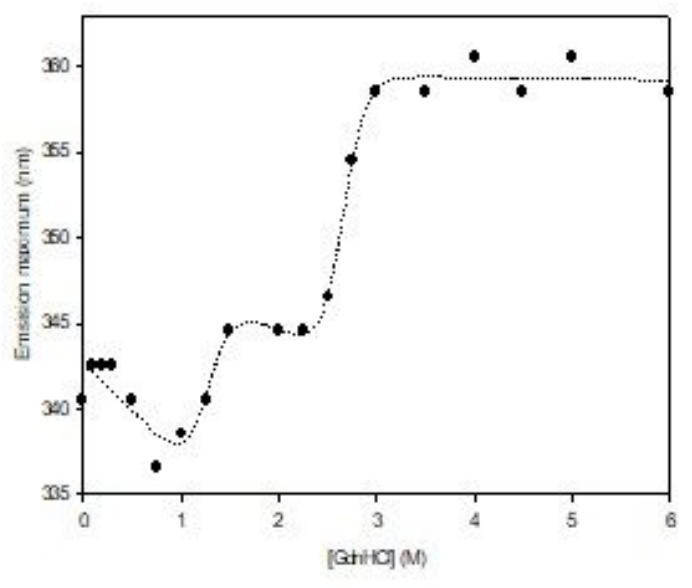

Figure 8

GdnHCl-mediated equilibrium unfolding of AAR. Upper panel represents GdnHCl-mediated equilibrium unfolding of AAR probed by CD spectroscopy. (A) Graph shows far-UV CD spectra of AAR at different $\mathrm{GdnHCl}$ concentrations. (B) Graph shows the GdnHCl-induced unfolding profile of AAR $(3.5 \mu \mathrm{M})$ 
monitored by far-UV CD at $222 \mathrm{~nm}$ at different varying concentration of denaturant. The intercept and slope of baselines, of the unfolding transition curve, were used for fitting of data in Equation 11 (data analysis section). Middle panel represents $\mathrm{GdnHCl}$-mediated equilibrium unfolding of AAR probed by intrinsic fluorescence spectroscopy. (C) Graph shows fluorescence emission spectra of AAR monitored from 310 to $400 \mathrm{~nm}$ when excited at $295 \mathrm{~nm}$ at different concentration of $\mathrm{GdnHCl}$. The inset graph represents the fluorescence intensity of AAR at $340 \mathrm{~nm}$ when subjected to varying AAR concentration. (D) Graph shows the change in the emission maximum ( $\lambda$ max) at different concentration of urea. The intercept and slope of baselines, of the unfolding transition curve, were used for fitting of data in Equation 11 (data analysis section). (E) Panel represents theoretical curve showing different population during $\mathrm{GdnHCl}$-induced unfolding pathway of AAR. Graph shows the $\mathrm{GdnHCl}$ concentration dependence of populations of native $(\mathrm{N})$, intermediate $(\mathrm{I})$ and unfolded state $(\mathrm{U})$ of AAR calculated from the thermodynamic parameters listed in Table 3. 

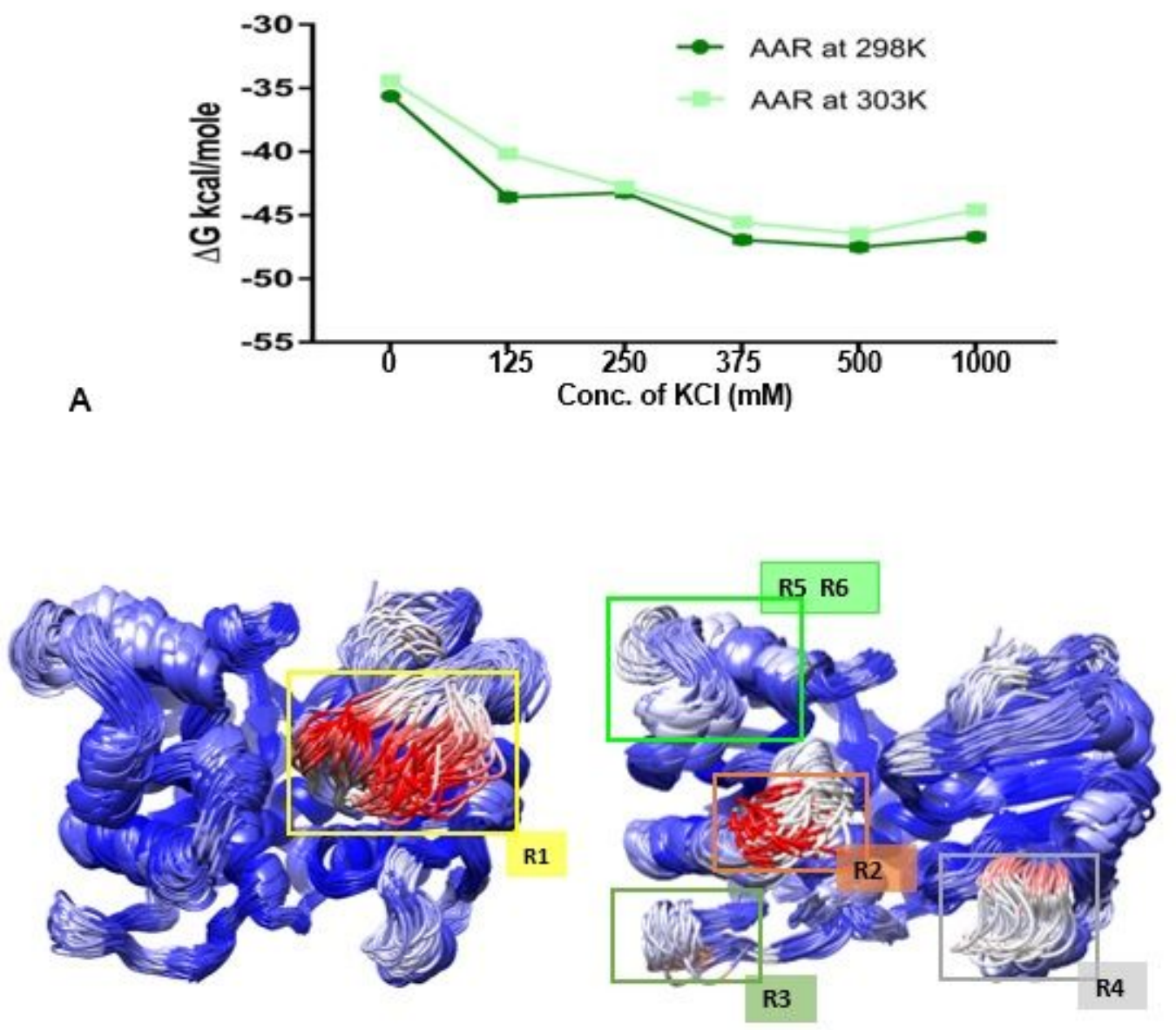

B

AAR at $0 \mathrm{M} \mathrm{KCl}$

C

AAR at $375 \mathrm{mM} \mathrm{KCl}$
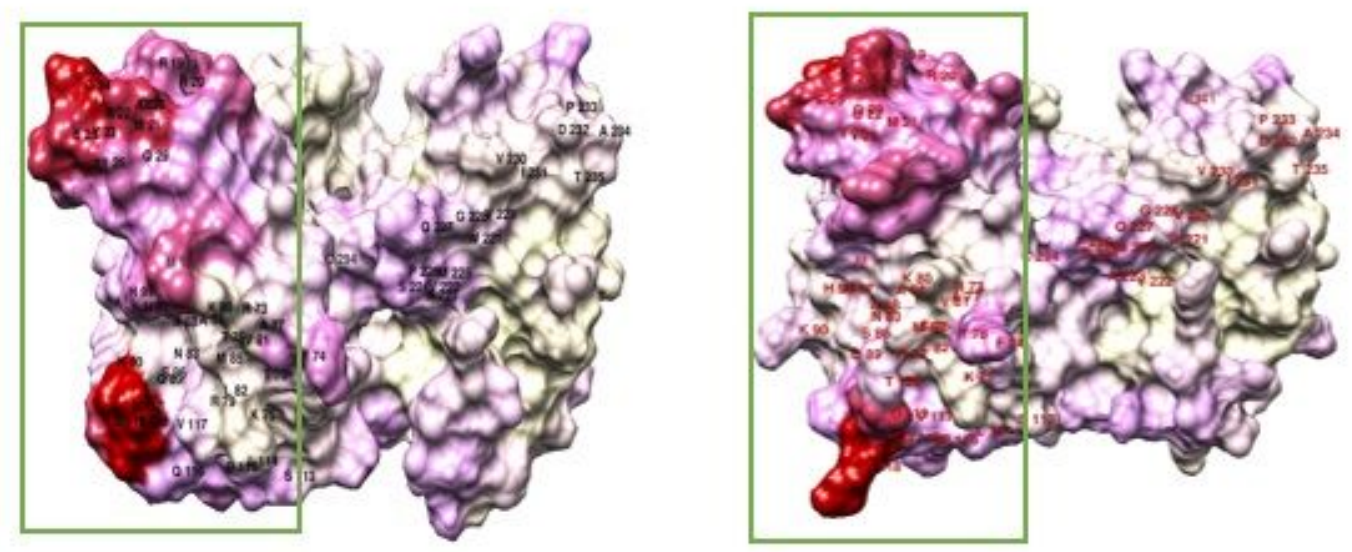

D

AAR at $0 \mathrm{M} \mathrm{KCI}$

E

AAR at $375 \mathrm{mM} \mathrm{KCl}$

\section{Figure 9}

Molecular dynamics simulations of AAR. (A) The free energy values of AAR subjected to different concentrations of $\mathrm{KCl}$ ranging from 0 to $1000 \mathrm{mM}$. Energies were derived from Molecular Mechanics Generalized Born Surface Area (MMGBSA) calculations. (B, C) The cluster representations of AAR at 0 M and $375 \mathrm{mM} \mathrm{KCl}$ over a 200-ns trajectory at 2-ns intervals. The enzymes are colored by RMSF, where red represents the highest fluctuations, and blue represents the lowest fluctuations. Highlighted R1, R2, R3, 
R4, R5, and R6 correspond to (A223-V230), (L69-R72), (L114-E123), (A188-N190), (A14-D16), and (D28S35) regions of AAR respectively. (D, E). The surface view of the cluster representative of AAR subjected to $0 \mathrm{M}$ and $375 \mathrm{mM} \mathrm{KCl}$ solvent environment.

\section{Supplementary Files}

This is a list of supplementary files associated with this preprint. Click to download.

- 20201011SupportingInformation.docx 